\title{
Direct Acting Antivirals for the Treatment of Chronic Viral Hepatitis
}

\author{
Peter Karayiannis \\ Section of Hepatology and Gastroenterology, Department of Medicine, Imperial College, St Mary's Campus, \\ London W2 1PG, UK
}

Correspondence should be addressed to Peter Karayiannis; p.karayiannis@imperial.ac.uk

Received 17 September 2012; Accepted 8 October 2012

Academic Editors: M. Clementi and W. Vogel

Copyright (C 2012 Peter Karayiannis. This is an open access article distributed under the Creative Commons Attribution License, which permits unrestricted use, distribution, and reproduction in any medium, provided the original work is properly cited.

\begin{abstract}
The development and evaluation of antiviral agents through carefully designed clinical trials over the last 25 years have heralded a new dawn in the treatment of patients chronically infected with the hepatitis B and C viruses, but not so for the D virus (HBV, $\mathrm{HCV}$, and HDV). The introduction of direct acting antivirals (DDAs) for the treatment of HBV carriers has permitted the longterm use of these compounds for the continuous suppression of viral replication, whilst in the case of HCV in combination with the standard of care [SOC, pegylated interferon (PegIFN), and ribavirin] sustained virological responses (SVRs) have been achieved with increasing frequency. Progress in the case of HDV has been slow and lacking in significant breakthroughs. This paper aims to summarise the current state of play in treatment approaches for chonic viral hepatitis patients and future perspectives.
\end{abstract}

\section{Introduction}

Conservative estimates of the number of individuals worldwide who are thought to be chronically infected with either HBV or HCV are placed at over 350 [1] and 200 [2] million, respectively. It has long been established through epidemiological surveys that these patients are at increased risk of developing cirrhosis, hepatic decompensation, and hepatocellular carcinoma (HCC). About 1 million people die per year as a result of HBV-related liver pathologies [3]. In resource-limited countries, HBV infection accounts for $30 \%$ of cirrhotic patients and $53 \%$ of those with HCC [4]. On the other hand, HCV is responsible for approximately 350000 deaths every year [5]. The only means of preventing these un-necessary deaths is therapeutic intervention through the use of immune modulators and direct acting antivirals (DDAs). The ultimate goals of treatment are to achieve a sustainable suppression of replication and remission of liver disease in the case of HBV, and complete eradication of the virus from the liver in the case of HCV.

For many years, the only choice for treatment was interferon alpha (IFN $\alpha$ ), lymphoblastoid initially and recombinant subsequently, both of which have more recently been superceded by the pegylated form (PegIFN), which requires intramuscular injection only once a week as opposed to three times a week with the previous forms. Interferon has not only immunomodulatory, but also antiproliferative and antiviral effects. It acts by promoting cytotoxic $\mathrm{T}$-cell activity for lysis of infected hepatocytes and by stimulating cytokine production for control of viral replication.

DDAs on the other hand constitute a more recent development based on increasing knowledge of the molecular biology of the hepatitis viruses. In the case of $\mathrm{HCV}$, the resolution of the 3-dimensional structure of important viral enzymes such as the NS3 serine protease and the RNAdependent RNA polymerase (RdRp), and the in vitro models of viral replication that have allowed the study of virus entry, replication, morphogenesis, and identified host factors that are required for this process, have been invaluable in the design and testing of drugs under development. Such drugs act directly as viral lifecycle inhibitors. The current choices of treatment will be reviewed in turn for each virus, as well as results from current clinical or preclinical trials with other agents in development, and which most likely will truly revolutionise future treatment approaches. 


\section{Hepatitis B Virus}

2.1. Virology. HBV is the prototype virus of the Hepadnaviridae, a name which signifies the hepatotropism and DNA nature of the genome of its members. The mature virion or Dane particle measuring $45 \mathrm{~nm}$ in diameter is spherical in nature and consists of an outer envelope comprised of the hepatitis B surface proteins (HBsAg) in a lipid bilayer derived from the host. The envelope encloses the nucleocapsid of the virus which is composed of the self-assembling core protein (HBcAg). This in turn encloses the viral genome which is a relaxed circular, partially double stranded DNA molecule of $3.2 \mathrm{~kb}$ in length. All of the nucleotide sequence of the genome is organised in 4 partially or totally overlapping open reading frames (ORFs), [6] which are transcribed with the help of two enhancer elements and four promoters within the genome. The Pre-S/S ORF encodes the three envelope glycoproteins which are known as the large (L), middle (M), and small (S) HBsAgs. All three proteins share the $\mathrm{S}$ domain, whilst the $\mathrm{L}(\mathrm{PreS} 1+\mathrm{PreS} 2+\mathrm{S})$ and $\mathrm{M}(\mathrm{PreS} 2+\mathrm{S})$ proteins have $\mathrm{N}$ terminal extensions as indicated [7]. The $\mathrm{S}$ domain contains the major hydrophilic region known as the $\alpha$ determinant which confers group specificity, a cluster of B-cell epitopes between amino acid positions 90-160. This constitutes the main target of neutralising antibodies, both natural and vaccine induced [8]. In addition, subviral particles in the form of $22 \mathrm{~nm}$ spheres and filaments composed entirely of $\mathrm{HBsAg}$ are released into the circulation in numbers up to a million in excess of the infectious Dane virions [7].

The amino acid sequence of the $S$ protein has allowed the identification of at least 8 genotypes of the virus, the most common of which are genotypes A-F.

Genotype A is seen mostly in Northern Europe, whilst $\mathrm{D}$ in Southern Europe, the Middle East, and Indian subcontinent $[9,10]$. Genotypes B and C are prevalent in the Far East, whilst genotypes E and F are found in Africa and South America, respectively [11]. The predominant genotypes in The United States are A and C [12].

The precore/core ORF encodes for two translation products, namely, the longer precore polypeptide initiated at the first AUG and which constitutes the precursor of the soluble hepatitis $\mathrm{B}$ e antigen ( $\mathrm{HBeAg}$ ), and the core protein or HBcAg. The synthesis of the latter utilises the second in frame AUG of the ORF. The HBeAg is formed by proteolytic cleavage of its N-terminal 19 amino acids which constitute a signal peptide and truncation of its C-terminus, through the action of peptidases within the lumen of the endoplasmic reticulum (ER) network resulting in its secretion. $\mathrm{HBeAg}$ is thus a nonstructural protein, not essential for viral replication, a marker of infectivity, and with tolerogenic and immune modulating activity that plays a significant role in viral persistence. The shortest ORF encodes for the $\mathrm{X}$ protein which is essential for viral replication and has transactivating potential. The longest ORF is that for the polymerase, which has four domains; the $\mathrm{N}$-terminus is occupied by the terminal protein which is involved in priming DNA synthesis followed by the spacer region, then the reverse transcriptase (rt)/DNA polymerase domain, and finally the RNAse $\mathrm{H}$ domain at the C-terminus. All RNA transcripts involved in the translation of these proteins are coterminal, polyadenylated, and capped $[6,7,13]$.

2.2. Replication. The hepatocyte receptor responsible for virus attachment remains unknown to this date. In contrast, amino acid positions $21-47$ of the Pre-S1 have been implicated in virus binding to the hepatocyte membrane $[14,15]$. A domain within S may assist in this process by bringing the virion in close contact with the cell membrane, and thus facilitating the specific interaction of the Pre-S1 domain with its receptor [16]. Following internalisation the virion is uncoated in the cytosol, the naked core particles are trafficked to the nuclear pore through which the genome penetrates into the nucleoplasm, where it is converted into a double-stranded covalently closed circular DNA (cccDNA) molecule, following removal of the covalently bonded terminal protein from the negative (-)-DNA strand and repair of the nick, as well as completion and ligation of the shorter positive $(+)$-strand $[6,7,13,17]$. Intrahepatic cccDNA load ranges from $0.1-1$ copy per cell, or 10-1000 copies per infected cell, depending on the HBeAg status of the patient as explained below. cccDNA remains in episomal form and in its transcriptionally active state associates with histones and other proteins, and through recruitment of a number of liver specific transcription factors serves as the template for viral transcript synthesis by host RNA polymerase II. Most antiviral agents so far have been unable to prevent the replenishment of the cccDNA pool from genonic HBVDNA recycled from immature core particles in the cytoplasm to the nucleus, or to radically eliminate cccDNA-containing hepatocytes [18]. This persistence explains the rather rapid rebound in serum HBV-DNA after cessation of antiviral treatment and the reactivation of $\mathrm{HBV}$ infection following immunosuppression of individuals in spite of the presence of immune clearance markers.

The pregenomic RNA (pgRNA) is one of two RNA transcripts longer than genome length $(3.5 \mathrm{~kb})$, which is the template for (-)-DNA strand synthesis as well as the message encoding both the core and polymerase proteins (Figures 1 and 2) [19]. The polymerase engages epsilon $(\varepsilon)$, a secondary RNA structure at the $5^{\prime}$ end of the pgRNA, [20] triggering encapsidation of the complex by the core protein. Thus subsequent steps in virus nucleic acid replication take place within the nucleocapsid $[6,7,13,21]$. As a consequence of the terminal redundancy of the pgRNA, the epsilon sequence and flanking region containing direct repeat 1 (DR1) are duplicated (Figure 2). The bulge of the $\varepsilon$ structure serves as a template for the synthesis of a 3 nucleotide long DNA primer, which is covalently attached to the polymerase though a tyrosine residue of the terminal protein (position 96) [22, 23]. This event involves the $\varepsilon$ structure at the $5^{\prime}$ end of the pgRNA, and is then followed by the translocation of the polymeraseprimer complex to the $3^{\prime}$, where the primer hybridises to a homologous region of DR1. This in turn initiates (-)-DNA strand synthesis by reverse transcription as the complex proceeds towards the $5^{\prime}$ end of the pgRNA. Concurrently, the RNA template is degraded by the RNAse $\mathrm{H}$ activity of the polymerase, except for the final 18 or so ribonucleotides. 


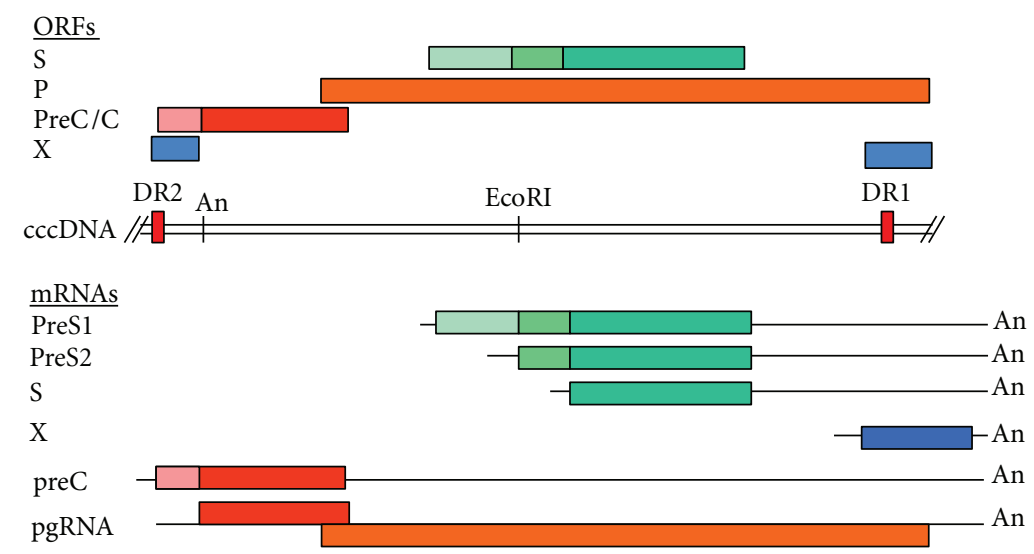

FIGURE 1: The closed covalent circular DNA of HBV depicted in linear form and showing positions of the direct repeats (DR) 1 and 2, and the polyadenylation signal (An). The open readings frames encoding for the surface (S), polymerase (P), X and Precore/core proteins are shown above, whilst the RNA transcripts are shown below the cccDNA. The various RNA transcripts terminate at the common polyadenylation signal.

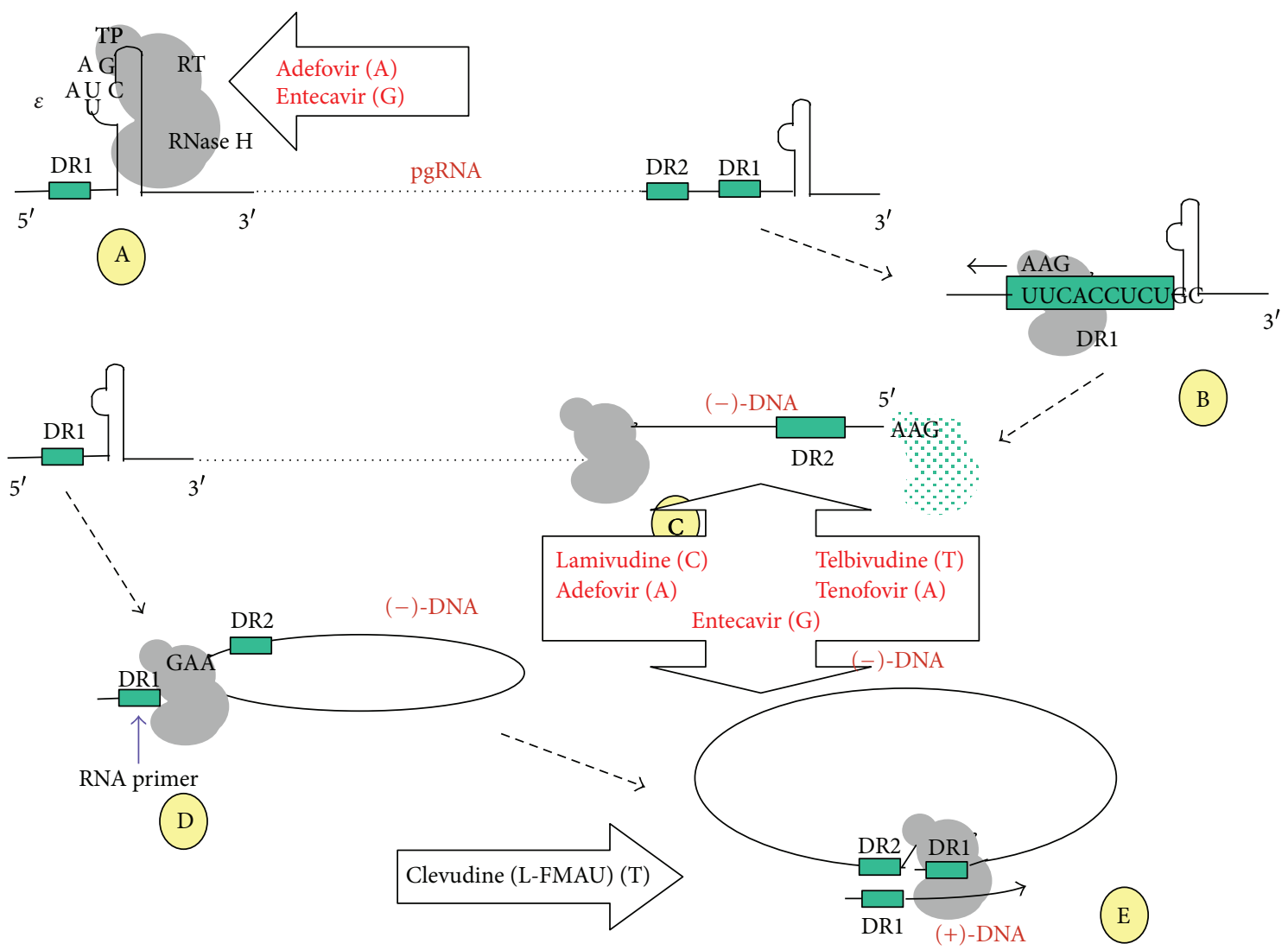

FIGURE 2: The replication strategy of hepatitis B virus and stages of: (A) binding of the viral polymerase to $\varepsilon$ and synthesis of a short primer using as template the nucleotide sequence of the bulge as shown. (B) Translocation of the polymerase/primer complex to the $3^{\prime}$ end of the pgRNA and base-pairing with DR1. (C) (-)-DNA strand synthesis and degradation of the pgRNA template by the RNase $\mathrm{H}$ domain of the polymerase, apart from its terminal 18 or so bases. These bases constitute the RNA primer which initiates (+)-DNA strand synthesis (D). Translocation of the primer to the $5^{\prime}$ end of the newly synthesised (-)-DNA strand and annealing with the homologous DR2 region leads to $(+)$-DNA strand synthesis. This proceeds in the direction shown by the arrow, which necessitates yet another translocation event to the $3^{\prime}$ end of the (-)-DNA strand. Both of these events are most likely facilitated by the effective circularisation of the (-)-DNA strand. This becomes possible, as a result of the covalent attachment of the $5^{\prime}$ end of the strand to the polymerase, which is maintained during continued synthesis of the (-)-DNA strand. Thus, the two ends of the strand are brought into close proximity with each other (E). Points of action of nucleos(t)ide analogues are shown by open arrows. 
A second translocation event then occurs during which the ribonucleotide primer hybridises with the DR1 region at the $5^{\prime}$ end of the newly synthesised (-)-DNA strand. A template exchange occurs that allows the (+)-DNA strand synthesis to proceed along the $5^{\prime}$ end of the complete (-)-DNA strand, effectively circularising the genome [21]. Pores on the surface of the capsid facilitate nucleotide entry for DNA strand synthesis, including nucleos(t)ide analogues during treatment [24]. Envelopment of the mature nucleocapsid by budding through the ER membrane, [25] leads to exhaustion of the nucleotide pool within the capsid leaving the (+)-DNA strand incomplete.

2.3. Mutations. Natural stable variants of the virus give rise to well-recognised serological subtypes and genotypes [26]. However, HBV has a higher mutation rate than other DNA viruses $\left(2 \times 10^{-4}\right.$ base substitutions per site per year), [27] through error prone steps in the replication cycle of the virus. These may occur during pgRNA synthesis by the cellular RNA polymerase II, as RNA polymerases show inherently low copying fidelity, but also during reverse transcription due to the lack of proof reading capacity by the viral polymerase. Fluctuations in the composition of the intracellular nucleotide pools are another possible contributing factor. A lot of these mutations are lethal to the virus, but those which offer it a replication advantage, facilitate immune escape, or cause resistance to antiviral drugs, as explained later, can be preferentially selected.

A G1896A substitution in the precore region creates a premature termination codon (precore stop-codon variant) that abrogates HBeAg production [28-30]. The variant is seen in genotype $\mathrm{D}$ which prevails in the Mediterranean basin, Middle East, and Indian subcontinent, genotypes B and C in countries of the Far East, and genotype $\mathrm{E}$ in Africa. This mutation is rarely detected in genotype A strains found in Northern Europe and North America. A double mutation in the core promoter region (A1762T, G1764A) [31] downregulates transcription of the precore mRNA encoding the $\mathrm{HBeAg}$ precursor protein, whilst pgRNA synthesis is upregulated [32]. These variants predominate in $\mathrm{HBeAg}$ negative patients with detectable levels of HBV-DNA, [33] may cause frequent exacerbations with fluctuating transaminase levels, [34-36] and have important implications in the treatment of such patients with antiviral agents [34].

2.4. Patient Groups. The main routes of HBV transmission are not only perinatal, percutaneous, and sexual, but also by contact with open cuts and sores, as may occur between children in hyperendemic areas [37]. The risk of progressing to chronicity following acute infection is age dependent. Over $90 \%$ of newborns to $\mathrm{HBeAg}$ positive mothers, $25-30 \%$ in infants and very young children, and around 5\% of adults are at risk of becoming chronic carriers after exposure, [3840] defined as the persistence of HBsAg in serum for longer then six months [41]. The natural history of chronic hepatitis $\mathrm{B}(\mathrm{CHB})$ may progress through four phases which in turn are the immune tolerant, the immune clearance, the inactive or nonreplicative, and the reactivation or immune escape phases. These phases do not occur in all individuals and this may depend on the age and route of exposure and may not be sequential [42].

The immune tolerant phase is normally found in patients who are exposed to the virus at a young age and is characterised by HBeAg positivity, high HBV-DNA levels (>20000 IU/mL), normal or near normal ALT levels, nor$\mathrm{mal} / \mathrm{minimal}$ histological activity, and HBsAg levels ranging from $4.5-5 \log \mathrm{IU} / \mathrm{mL}$. This phase may last for 20-30 years [43-46]. In contrast, this phase in those exposed to the virus in adulthood is short and leads to the immune clearance phase which is characterised once again by $\mathrm{HBeAg}$ positivity, elevated serum ALT levels associated with histological damage, fluctuating HBV-DNA levels, and lower levels of HBsAg $(4.3 \log \mathrm{IU} / \mathrm{mL})[47,48]$. During this period the virus comes under immune attack with emergence of the precore and core promoter mutants. This sequence of events culminates in $\mathrm{HBeAg}$ seroconversion to anti-HBe that leads into the immune control or nonreplicative phase with extremely low or undetectable HBV-DNA and normal ALT levels. A subset of patients however, for reasons that remain unknown reactivate viral replication forming a group that is referred to as the $\mathrm{HBeAg}$-negative $\mathrm{CHB}$, characterised by HBV-DNA levels $>2000 \mathrm{IU} / \mathrm{mL}$, fluctuating ALT levels once again, liver damage and higher levels of HBsAg (3.5 $\log I U / \mathrm{mL})$ than during the immune control phase [48]. The patients in the phases of immune clearance and immune escape are the most likely candidates for antiviral treatment with currently approved drugs, including difficult to treat groups such as cirrhotics, immunosuppressed patients as a consequence of organ transplantation and patients with HIV infection.

\section{Desirable End Points of Treatment}

Successful antiviral treatment relies on the achievement of the following biochemical, virological, and histological endpoints. These are normalisation of ALT levels, suppression of HBV-DNA to undetectable levels monitored by real-time PCR assays with a lower limit of detection of $10-20 \mathrm{IU} / \mathrm{mL}$ (both in $\mathrm{HBeAg}$-positive and-negative $\mathrm{CHB}$ ), loss of $\mathrm{HBeAg}$ with or without development of anti-HBe, and a decrease in the necroinflammatory score by $\geq 2$ points with no worsening in fibrosis. Loss of HBsAg with or without development of anti-HBs is a more desirable outcome but not so easily achievable. Spontaneous HBsAg loss and/or seroconversion is a rare event in $\mathrm{CHB}$ occurring at an annual rate of around $1 \%$ [49].

\section{Pegylated Interferon (PegIFN)}

Although IFN is not a DAA, for the sake of completion and comparative purposes will be dealt with here in brief. Recombinant or standard IFN licensed for the treatment of CHB nearly two decades ago has been replaced with PegIFN $\alpha 2$ a (Pegasys) with improved pharmacokinetics, more potent and once-a-week subcutaneous injection only as opposed to 3 of its prototype. Two phase III studies compared PegIFN to lamivudine (LMV, a nucleoside analogue) or a combination 
of both for 48 weeks in $\mathrm{HBeAg}$-positive and-negative patients $[50,51]$. In the former, PegIFN with or without LMV was shown to be superior to LMV monotherapy, [50, 52, 53] although a higher log reduction of HBV-DNA was observed with the combination at 48 weeks but not at the end of followup (2-4.5 versus 4-7.2 copies/mL) [50, 52]. Long-term followup of European and Far Eastern patients indicated that $19 \%$ had undetectable levels of HBV-DNA, HBeAg loss had occurred in $37 \%$, and more importantly $11 \%$ had lost HBsAg after a mean of 3.5 years after cessation of treatment. There were differences though depending on genotype; HBsAg loss was significantly higher in genotype A than non-A infection ( $28 \%$ versus $3 \%)$. What is more, among initial responders durable loss of HBeAg was recorded in $80 \%$ of patients and HBsAg loss in $30 \%$ of them. This is in contrast to the $2.4 \%$ of HBsAg loss seen after 5 years in patients with genotypes B and $\mathrm{C}$ from Hong Kong, with similar levels of durable HBeAg loss [54]. Other than genotype, a high level of ALT and a low level of HBV-DNA appear to be good predictors of response $[50,52]$.

In the case of $\mathrm{HBeAg}$ negative patients, similar studies showed after 48 weeks of treatment in patients who received PegIFN alone or in combination with LMV had a significantly higher rate of sustained, off-treatment responses, which were maintained when the patients were reevaluated 3 years after stopping treatment $[51,55,56]$. Younger age, female sex, a high level of ALT, a low level of HBV-DNA, and genotypes $\mathrm{B}$ and $\mathrm{C}$ have been shown to be associated with a favourable response to treatment [57].

More recently, quantitative measurement of HBsAg levels during treatment has been shown to be a useful tool in monitoring PegIFN treatment efficacy. An on treatment decline of HBsAg of $>1 \log \mathrm{IU} / \mathrm{mL}$ at 24 weeks of treatment had a high predictive value of a sustained response $[48,58]$. Moreover, having an HBsAg level of $<10 \mathrm{IU} / \mathrm{mL}$ at the end of therapy and a $1 \mathrm{log} \mathrm{IU} / \mathrm{mL}$ drop in levels during treatment were strong predictors of durability of response and loss of HBsAg 3 years after treatment discontinuation [59].

\section{Nucleos(t)ide Analogues (NAs)}

Currently five NAs are licensed for the treatment of CHB. These include in chronological order of licensing LMV, adefovir dipivoxil (ADV), entecavir (ETV), telbivudine (TBV), and tenofovir disoproxil fumarate (TFV). NAs act by suppressing HBV replication at the level of DNA synthesis, and this because they are chemically synthesised drugs which are able to mimic natural nucleos(t)ides. As such, they are incorporated into newly synthesised HBV-DNA causing chain termination (Figure 2), and thus inhibiting viral replication. In addition, some of them competitively inhibit the DNA-dependent and reverse transcriptase activity of the viral polymerase. For this to occur, the NAs need to be phosphorylated within cells to their triphosphate counterparts and possible steps in the life cycle of HBV that may be inhibited include the synthesis of the (-)-DNA strand by reverse transcription and that of the $(+)$-DNA strand, as well as the synthesis of the primer for initiation of DNA synthesis (Figure 2). Experiments in woodchucks suggest that nucleoside analogue treatment does not have an appreciable effect on the cccDNA pool in hepatocytes [60].

5.1. Lamivudine (LMV). Lamivudine is the L-enantiomer of the deoxycytidine analogue $2^{\prime}, 3^{\prime}$-dideoxy- $3^{\prime}$-thiacytidine (3TC) and was the first NA to be approved for the treatment of CHB (1998) [61, 62]. Widely used when first licensed, LMV is not as widely used nowadays in view of the newer NAs with a better genetic barrier record to resistance. Since LMV acts by terminating viral DNA synthesis $[62,63]$ and competitively inhibiting the viral polymerase/rt, [63] it is equally effective in patients of any race, but also against both the wild-type virus and precore/core promoter variants [56, 64-67]. LMV is administered orally and the recommended dose for adults is $100 \mathrm{mg}$ per day. LMV is still in use in poor resource countries.

Several randomised clinical trials of LMV monotherapy in $\mathrm{HBeAg}$-positive patients showed that 1 year of treatment induced $\mathrm{HBeAg}$ seroconversion in $16-18 \%$ of them, compared to $4-6 \%$ in controls [68-70]. Histologic improvement by at least 2 points in the histological activity score was observed in $49-56 \%$ and $25 \%$ of treated and control patients, respectively. $\mathrm{HBeAg}$ seroconversion rates increased with length of therapy rising from $17 \%$ at 1 year to $27 \%, 36 \%$, and $47 \%$ at years 2,3 and 4 respectively [71-73]. The durability of $\mathrm{HBeAg}$ seroconversion in lamivudine treated patients is variable ranging in some studies between 38-73\%, [72-74] but can be consolidated by extending treatment for 6 months or more $[75,76]$.

LMV treatment of $\mathrm{HBeAg}$ negative patients achieved HBV-DNA undetectability in up to $72 \%$ of patients and ALT normalisation in $65-96 \%$ of patients at the end of treatment $[56,64,77-83]$. Similarly, there was a beneficial impact on the histological picture in $60 \%$ of patients, and slow down or even improvement in the fibrosis score in $11-35 \%$ of patients $[56,83,84]$. The arrest or reduction in the immune-mediated inflammatory response in the liver and the reduction in scarring, not only benefited the fibrosis score, but also resulted in a decrease in the incidence of HCC [8587]. Patient relapse rates after 1 year of followup amounted to $45-74 \%$ (sustained response of only $11-20 \%$ ), hence the recommendation for long-term use in these patients and in $\mathrm{HBeAg}$ positive patients not achieving $\mathrm{HBeAg}$ loss. The efficacy of LMV for treatment periods longer than 12 months in $\mathrm{HBeAg}$ negative patients indicated drops of $14-36 \%$ by 24 months in comparison to those at 12 months [64, 79, 80, 88].

The most important predictor of a favourable response following LMV treatment is the pretreatment ALT level $[89,90]$. The major drawback of LMV is the high rate of emergence of drug resistant variants that can lead to virological and biochemical relapse. Breakthrough infections have been recorded in $27 \%$ of $\mathrm{HBeAg}$-positive patients after 1 year of treatment, [68-70] increasing to $38 \%, 49 \%$, and $66 \%$ for years 2,3 , and 4 , and up to $76 \%$ at year 8 , respectively [ $71-$ $73,87]$. Lamivudine resistant variants also arise in $\mathrm{HBeAg-}$ negative patients ranging from $27 \%$ at 1 year to $70-80$ by year $5[56,64,78,80]$. Emergence of the lamivudine resistant 
variants may be accompanied by acute exacerbation of liver disease $[91,92]$. Moreover, HBeAg seroconversion has been reported to occur in about a quarter of the patients with breakthroughs, who continue treatment $[71,91]$.

The rt/DNA polymerase domain contains at least 5 subdomains (A-E) which are spatially separated, but closely associated with the normal function of the protein. Subdomain C contains the characteristic YMDD (tyrosinemethionine-aspartate-aspartate) motif of the catalytic site [93]. LMV resistance is associated with amino acid substitutions primarily in subdomain $\mathrm{C}$ and may be accompanied by others in subdomain B $[92,94,95]$. Substitutions in subdomain $\mathrm{C}$ affect the YMDD motif, and include rtM204I (YIDD) and rt M204V (YVDD) [69, 73, 94, 96-100]. Viruses with these mutations are less replication fit than the wild-type virus $[101,102]$. It is postulated that an $\mathrm{rtL} 180 \mathrm{M}$ mutation in subdomain B accompanying the rtM204V change, [94, 97, $99,100]$ restores replication competency, [102] as rtV173L also in subdomain B may do so also $[92,103,104]$. One other mutant, rtA181T/V has been shown to be resistant to LMV following prolonged treatment, [105] with cross-resistance to ADV [106].

5.2. Adefovir Dipivoxil (ADV). Adefovir (Hepsera) or bispivaloyloxymethyl-9-(2-phosphonyl-methoxyethyl) adenine (PMEA) is an NA of adenosine monophosphate and was approved in 2002 for the treatment of CHB (10 mg/day). Adefovir inhibits HBV replication, [107, 108] but appears to be less potent than other NAs with regard to HBV-DNA reduction. Its efficacy has been assessed in the clinical setting, and has been shown to be active against LMV resistant mutants [109-116]. Treatment for one year led to an HBeAg seroconversion rate of $12 \%$, whilst histological improvement was seen in $53 \%$ of $\mathrm{HBeAg}$ positive patients [117]. HBeAg serconversion was sustained in $91 \%$ of these patients [76, $118]$. $\mathrm{ADV}$ is also effective in $\mathrm{HBeAg}$ negative patients with 51\% and 64-69\% achieving HBV-DNA undetectability and histological improvement, respectively [119]. Prolonged treatment leads to emergence of resistance with two main mutations; rtA181T/V and rtN236T [120]. Genotypic resistance is less frequent than LMV with an incidence of $0 \%, 3 \%$, $11 \%, 18 \%$ and $29 \%$ after $1,2,3,4$, and 5 years of treatment, respectively, in $\mathrm{HBeAg}$ negative patients [121]. ADV has now been superceded by TFV use instead.

5.3. Entecavir (ETV). Entecavir is a nucleoside analogue of adenosine monophosphate which was licensed for the treatment of CHB in 2005. It is superior to LMV and is used at a dose of $0.5 \mathrm{mg} /$ day and $1 \mathrm{mg} /$ day for treatment naïve and LMV resistant patients, respectively. It has a potent antihepadnaviral activity, [122-124] as demonstrated against both $\mathrm{HBeAg}$ positive and negative patients. ETV was compared to LMV in treatment naïve $\mathrm{HBeAg}$ positive patients after 48 weeks of treatment and showed a 6.98 versus $5.4 \mathrm{log}$ drop in HBV-DNA in copies/mL [125]. In another trial, treatment for 52 weeks resulted in a reduction in HBV-DNA to $<400 \mathrm{IU} / \mathrm{mL}$, histological improvement, and normalisation of ALT levels in 67\% versus 36\%, $72 \%$ versus
$62 \%$, and $78 \%$ versus $70 \%$, compared to LMV treated patients once again [126]. HBeAg seroconversion rates however were very similar at $21 \%$ versus $18 \%$. Similar results were obtained in a trial comparing ETV to ADV [127].

Similar results were obtained in $\mathrm{HBeAg}$ negative patients with indefinite treatment when comparing ETV to LMV; HBV-DNA suppression was recorded in $91 \%$ versus $73 \%$ and histological improvement in $70 \%$ versus $61 \%[128,129]$. After 5 years of treatment ETV maintained HBV-DNA suppression at levels $<300$ copies/mL in $94 \%$ of patients, [130] whilst $84 \%$ of patients had improvements in the their fibrotic scores after 6 years of treatment [131].

HBsAg loss was seen in $1.7 \%$ of ETV versus $1.1 \%$ of LMV patients treated for 48 weeks, rising to $5 \%$ versus $3 \%$ at week 96 [132]. The probability of this happening appears to be higher in genotype $\mathrm{A}$ and $\mathrm{D}$ infected male patients of Caucasian race, with early $\mathrm{HBeAg}$ seroconversion. In the case of $\mathrm{HBeAg}$ negative patients, ETV does not appear to have an impact on HBsAg loss [133].

ETV has a high genetic barrier with an extremely low incidence of resistance [134]. In treatment naïve patients, no resistance was detected by 2 years of treatment [135] and only $1.2 \%$ at 5 years $[130,134]$. Resistance was shown to arise in patients with preexisting LMV resistant quasispecies. In lamivudine refractory patients, ETV is effective in suppressing viral replication and leading to histological improvement [136]. However, the emergence of resistance is more frequent in this setting rising from $6 \%$ at year 1 to $15,36,46,51$ and $57 \%$ at years $2,3,4,5$, and 6 of treatment, respectively [135]. This requires the presence of rtM204V and rtL180 M, but not rtM204I, and of an additional mutation at rtI169T, rtT184G, rtS202I, or rt M250V for resistance against ETV to emerge $[137,138]$.

5.4. Telbivudine (TBV). Telbivudine is an analogue of thymidine which was approved for the treatment of CHB at a dose of $600 \mathrm{mg} /$ day in 2006. It was initially shown to induce significantly greater virological and biochemical responses than LMV following 1-year treatment [139]. In the phase III trials in $\mathrm{HBeAg}$ positive Chinese patients, HBeAg seroconversion stood at 22 and $30 \%$ after 1 and 2 years of treatment, whilst HBV-DNA suppression at 60 and $56 \%$ for the same time periods. Similarly in HBeAg negative patients HBV-DNA drops were 88 and $82 \%$ at year 1 and 2 , respectively [140, 141]. TBV was also shown to be superior to adefovir at suppressing HBV-DNA after 24 weeks of therapy [142].

Genotypic resistance against TBV has been reported at $4.4 \%$ and $21.6 \%$ at year 1 and 2 in HBeAg positive, whilst in $\mathrm{HBeAg}$ negative patients the figures were 2.7 and $8.6 \%$, [141] rising further by the 3rd year and thereafter [143, 144]. The rtM204I alone or in combination with rtL180 M confers resistance to TBV and therefore cross-resistance to LMV also. Resistance is lower depending on HBV-DNA level status of the patient, whether HBeAg positive $(<9 \log$ copies $/ \mathrm{mL})$ or HBeAg negative (<7 log copies/mL) [145]. Patients with resistance can still be switched to ETV, as the mutation associated with resistance to this drug is rtM204V and not rtM204I. 
TBV treatment has been associated with elevation of creatine kinase and myopathy in some patients, [141, 142, $146]$ and peripheral neuropathy if given in combination with PegIFN [147].

5.5. Tenofovir (TFV). Tenofovir disoproxil fumarate, an adenine analogue, was approved in 2008 for the treatment of $\mathrm{CHB}$ at a dose of $300 \mathrm{mg} /$ day. TFV has been shown to be superior in terms of HBV-DNA suppression, $\mathrm{HBeAg}$ seroconversion, and ALT normalisation in $\mathrm{HBeAg}$ positive patients when compared to ADV $[148,149]$. Undetectable levels of HBV-DNA (<400 copies/mL) were achieved in $76 \%$ and $93 \%$ of $\mathrm{HBeAg}$ positive and negative patients respectively; the figures for the ADV arm were $13 \%$ and $63 \%$ after 48 weeks of treatment [148]. Normalisation of ALT levels was seen in $68 \%$ versus $54 \%$, histological improvement in $67 \%$ versus $12 \%$, and $\mathrm{HBsAg}$ loss in 3.25 versus $0 \%$ in TFV and ADV treated patients, respectively [148]. Durability of response was almost $100 \%$ in both HBeAg positive and negative patients after 4 years of treatment [150-152]. More importantly, $\mathrm{HBeAg}$ loss after 4 years of treatment was recorded in $41 \%$ of patients and seroconversion in $29 \%$, whilst the figures for HBsAg loss and seroconversion were $10 \%$ and $7.5 \%$, respectively [151]. No resistance to TFV has been reported so far even after 5 years of followup [153].

TFV is generally well tolerated, but a few cases of Franconi syndrome have been reported [154]. Monitoring of serum creatinine and phosphorus levels is therefore advisable.

\section{Other Drugs and Drugs in Development}

Emtricitabine was initially approved for the treatment of HIV infection and shown to also have potency against HBV in both $\mathrm{HBeAg}$ positive and negative patients [155]. The drug is used in combination with tenofovir in HIV/HBV coinfected patients. Clevudine approved in South Korea and Philippines, was shown to be more potent than LMV at suppressing HBV-DNA [156]. However, its use has been associated with myopathy in the United States, and as both entecavir and tenofovir are more effective it seems unlikely that it would get approval in the West. Amdoxovir and ANA380 (LB80380) are two additional drugs which have shown promise in treatment naïve CHB patients or LMV resistant ones [157159]. Bay 41-4109 is a drug that appears to interfere with core particle assembly, $[160,161]$ but its full potential has not been evaluated yet.

\section{Conclusion}

NA monotherapy treatments are effective in suppressing $\mathrm{HBV}$ replication, leading to $\mathrm{HBeAg}$ seroconversion, normalisation of ALT levels, improvement in histology and in some cases, even loss of HBsAg. Certain groups of patients have benefited tremendously from the use of NAs, such as those with decompensated cirrhosis and chronic HBV patients undergoing liver transplantation. Patients who do not respond to monotherapy treatment protocols may benefit from combination therapies, as has been the case in HIV treatment. However, although not reviewed here NAs in combination with each other or with IFN have not resulted in any additive or synergistic effects. For this to happen, it may be necessary to combine drugs with different modes of action in the future. Development of resistance is a drawback, as it undermines long-term suppression of viral replication, and any histological and biochemical improvement. However, the use of ETV and TFV, both of which have a high genetic barrier to resistance, has largely overcome this problem.

\section{Hepatitis C Virus}

8.1. Virology. $\mathrm{HCV}$ is classified within the Flaviviridae family, under the genus of Hepacivirus. The virus particle has an outer envelope and an inner core, that in turn encloses the single stranded, positive sense RNA genome of the virus. The genome is $9.6 \mathrm{~kb}$ in length and contains a single ORF which is translated into a polyprotein of about 3000 amino acids long (Figure 3) [162]. The polyprotein is coand posttranslationally cleaved to yield the structural viral proteins from its $\mathrm{N}$-terminal end, whilst the $\mathrm{C}$-terminal two thirds of the protein yield the nonstructural (NS) ones. The structural proteins include the core $(\mathrm{C})$ protein responsible for the formation of the nucleocapsid and the two envelope glycoproteins E1 and E2. These and p7, which is thought to act as a viroporin, are processed by signal peptidases and a signal peptide peptidase resident within the ER lumen [163165]. NS2 is an autoprotease, dimers of which in conjunction with the N-terminal end of NS3, allow its cleavage from the nonstructural portion of the polyprotein, whilst the remainder of the nonstructural proteins (NS3, NS4A, NS4B, NS5A, NS5B) are cleaved by NS3 which acts as a serine protease. NS4A is a cofactor which after its cleavage associates with NS3 assisting in the processing at the NS4B/NS5A and NS5A/NS5B junctions. NS4B and NS5A appear to play key roles in viral replication as explained below, whilst the NS5B constitutes the RNA-dependent RNA polymerase (RdRp) of the virus. The NS3 serine protease which also functions as a helicase, as well as the RdRp, have been widely studied and their 3D structure resolved by X-ray crystallography [166]. Moreover, the development of subgenomic replicons and full infection systems such as the JFH1 strain have permitted the testing of potential DAAs in vitro $[167,168]$. Thus, DAAs that target these two enzymes, so crucial in the life cycle of the virus, have been developed as described below.

The ORF is flanked at either end by the $5^{\prime}$ and $3^{\prime}$ untranslated regions (UTRs), involved in translation and replication, respectively. The $5^{\prime}$ UTR forms a clover-leaf-like structure through intramolecular base-pairing known as the internal ribosome entry site, which recruits the translational ribosomal complex. Similarly the $3^{\prime}$ UTR has a triloop structure which recruits the replication complex for the synthesis of the full length replicative intermediate of negative sense [162].

8.2. Life Cycle. The virus circulates in blood in association with lipoproteins and is therefore referred to as a lipoviroparticle [169]. It binds to glycosaminoglycans and there 

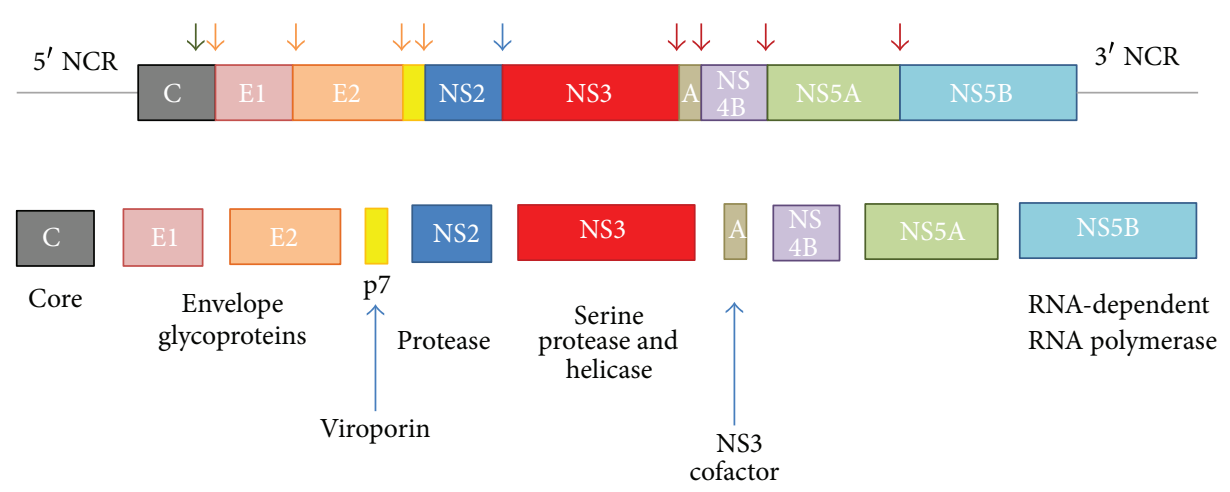

FIGURE 3: Genomic organisation of HCV showing the RNA, the polyprotein, and its products, following proteolytic cleavage. Cleavages by host signalases are shown in green and orange arrows, and those by virally encoded enzymes in blue (NS2/NS3) and brown (NS3/NS4A).

follows a multistep attachment process mediated through receptor or coreceptor binding, which includes a number of molecules such as CD81, a tetraspanin and SRB1, which is involved in selective lipid uptake $[170,171]$. Two junction proteins are also involved such as claudin-1 and occludin $[172,173]$. More recently two receptor tyrosine kinases, EGFR and EphA2, and Niemann Pick C1-like 1 cholesterol absorption receptor have also been shown to be involved in HCV entry $[174,175]$. The HCV particle is internalised by clathrin mediated endocytosis and following fusion of the viral envelope with early endosome membranes the capsid is released in the cytoplasm [176-178]. Uncoating and release of the RNA leads to the translation of the polyprotein and its processing to the various structural and NS components. The polyprotein is intimately associated with ER membranes so that E1 and E2 protrude into the ER lumen, whilst the NS3 through to NS5B, which constitute the replication complex, are associated with a network of membranes known as the membranous web. NS4B is instrumental in the formation of this web where RNA replication occurs. The core protein associates with lipid droplets and this association is very important in viral morphogenesis $[179,180]$. Packaging of positive sense RNA genomes in core nucleocapsids is followed by budding through the ER membrane resulting in the acquisition of the outer viral envelope containing the E1/E2 heterodimers [181]. The NS2 and p7 proteins are thought to play a role in successful viral assembly also [182-184]. Virus particle maturation and release is intricately associated with the VLDL assembly pathway. Thus, apart from VLDL, lipoviroparticles contain LDL and apolipoproteins $[169,181$, $185,186]$.

Host factors are also important during viral replication and assembly, such as cyclophillin A which is thought to interact with NS5A $[187,188]$. Another host factor is phosphatidylinositol 4 kinase III $\alpha$ (PI4KIII $\alpha$ ) which is associated with the membranous web, once again through interaction with NS5A [189]. These factors constitute targets for antiviral therapy.

HCV has a considerable amount of genetic variation which has allowed the division of virus isolates into six genotypes (Gt1-6) and over 100 subtypes. In addition, the RdRp lacks proof-reading capacity resulting in the introduction of point mutations during RNA replication. Thus, the virus circulates within an infected individual as a swarm of closely related variants known as quasispecies. Gt identification is an important determinant in instituting antiviral treatment. Moreover, quasispecies analysis has revealed that at least 9\% of treatment naïve patients have preexisting resistance mutations that would undermine antiviral therapy if instituted [190].

8.3. Standard of Care (SOC). Currently the approved SOC involves the use of PegIFNa2a or $-2 b[191,192]$ in combination with ribavirin (RBV), a nucleoside analogue of guanosine with broad antiviral activity [193]. PegIFN is administered once a week by intramuscular injection whilst $\mathrm{RBV}$ is taken orally twice a day. Weight based dosing of RBV has been shown to improve sustained virological responses (SVR), defined as undetectable HCV RNA 24 weeks after cessation of treatment of any duration [194]. RBV monotherapy has limited activity against HCV, but when used with PegIFN, it improves SVR significantly and has been the SOC for the last 10 years [195]. Depending on Gt, treatment duration lasts for 24 weeks for GT2/3 or 48 weeks for Gt1/4 leading to an SVR of $45 \%$ and $80 \%$, respectively $[192,196]$. A side effect of RBV use is the development of anaemia, which may compromise SVR if it becomes necessary to reduce the dosage.

Failure to achieve a $>2 \log$ decline in HCV RNA from baseline by week 12 is an indication for discontinuation of treatment, as the patient is unlikely to respond (null responders) [197]. On the other hand, patients with undetectable HCV RNA by week 4 (RVR, rapid virological response) are more likely to achieve SVR. Patients who experience a $>2 \mathrm{log}$ decline in HCV RNA by week 12 are said to have an early virological response (EVR), but if they fail to clear HCV RNA by week 24 are referred to as partial responders. Those who are negative for HCV RNA at the end of treatment but become positive during the 24-week followup are known as relapsers. Host factors including race, age, and fibrosis score, as well as HIV coinfection are known to be involved in poor responses to SOC treatment [191, 192, 198-201]. More recently, the discovery of a group of single nucleotide polymorphisms in the region of the IL28B gene (type III IFN) 
has widen the list of factors that can influence SOC outcome [202]. In particular, the CC genotype at the IL28B rs12979860 locus has proved the most powerful baseline predictor for up to $70 \%$ SVR in Gt1 patients as opposed to $25-30 \%$ with the CT or TT genotype.

8.4. DAAs. In 2011, two inhibitors of the NS3/4A serine protease were approved for the treatment of chronic $\mathrm{HCV}$ infection. These are telaprevir (TPV, Incivek) and boceprevir (BOC, Victrelis), both of which are active in patients with Gt1 infection. Both drugs are plagued with a number of adverse effects, but newer drugs in development are likely to overcome these problems, thus opening a new era in HCV treatment. The drugs are peptidomimetic, mimicking the polyprotein cleavage region, binding the active site of the enzyme, and thus preventing processing of the authentic substrate. There are two classes of these inhibitors which are the linear or covalent ketoamide derivatives and the macrocyclic (noncovalent) ones. TPV and BOC belong to the linear inhibitor group together with BI201335, whilst other inhibitors in development such as simeprevir (TMC435), danoprevir (ITMN191/R7227), vaniprevir (MK7009), GS9256, and others are macrocyclic.

Although both TPV and BOC are potent protease inhibitors (PIs) when given as monotherapy, resistant variants are selected very quickly from the pool of quasispecies, compromising their antiviral effect. As a result both drugs have been approved for treble therapy that includes PegIFN and RBV, as PegIFN with a broad antiviral action is able to keep any variant in check.

8.5. Telaprevir $(T P V)$. TPV is effective in both treatment naïve and treatment-experienced patients with Gt1 infection as shown in the PROVE 1-3 trials [203-206]. These trials established that higher response rates were obtained when TPV was added to PegIFN and RBV (PR), that RVR occurred more frequently and there were lower rates of relapse. RBV was shown to be an integral part of the combination, and dose reduction to $\leq 600 \mathrm{mg} /$ day did not compromise SVR rates [207]. In addition, the concept of response guided therapy whereby treatment was terminated early based on viral load measurement early in the course of treatment was introduced. The ADVANCE (phase 3) study compared 3 treatment arms that included $750 \mathrm{mg}$ of TPV every $8 \mathrm{~h}$ together with PR for 8 weeks followed by additional weeks of PR (T8PR), TPV, and PR for 12 weeks (T12PR) or PR for 48 weeks (PR48).

Patients who had undetectable HCV RNA at 4 or 12 weeks (extended RVR, eRVR) received a total of 24 weeks of treatment, whereas those who did not were treated for 48 weeks. SVR rates in both TPV arms stood at $75 \%$ and $69 \%$ for the T12 and T8 groups, respectively, compared with $44 \%$ in the control group (PR). Relapse rates were $9 \%$ in the TPV arms and $28 \%$ in the control arm. $58 \%$ of the patients in the T12 arm achieved eRVR and of these $89 \%$ also attained SVR. Looking at the results from the T12 arm, SVR rates in African-Americans were $62 \%$ and in patients with bridging fibrosis or cirrhosis also $62 \%$, as opposed to $25 \%$ and $33 \%$ in the PR arm, respectively. Discontinuation of treatment became necessary in $10 \%$ of the TPV treated patients as opposed to $7 \%$ of the controls, whilst rash and anaemia were the two main side effects of treatment with TPV. Grade 3 rash was seen in 5\% of the TPV treated patients and $29 \%$ reported anorectal problems versus $7 \%$ of controls.

In the illuminate study, all patients received 12 weeks of TPV followed by 12 or 36 weeks of PR if eRVR was achieved. SVR rates were $92 \%$ and $88 \%$ for the 12 and 36 weeks of $\mathrm{PR}$, respectively, thus indicating that the 24 -week treatment regimen was noninferior to the 48 weeks [208].

TPV was equally effective in treatment experienced patients as demonstrated in the REALIZE trial [209]. The trial had 3 treatment arms; one with 4 weeks PR followed by addition of TPV ( $750 \mathrm{mg}$ every $8 \mathrm{~h}$ ) for 8 weeks and then 32 weeks of PR only (delayed start), a second arm with treble therapy for 12 weeks followed by 36 weeks of PR (simultaneous start) and the control arm entailing 48 weeks of PR treatment. There was no difference in results between the TPV arms. Therefore pooling the results together, SVR rates were $85.5 \%$ for previous relapsers, $56.5 \%$ for partial responders, and $31 \%$ for null responders versus $24 \%, 15 \%$, and $5 \%$ in the control group, respectively. Presence of cirrhosis in null responders compromised SVR rates (14\%), whilst bridging fibrosis or cirrhosis in partial responders had higher SVR rates (44\%).

TPV is a potent inhibitor of CYP3A and therefore contraindicated in patients taking at the same time medicines that are highly dependent on CYP3A clearance, as high concentrations are associated with serious events. Other drugs include lovastatin, simvastatin and atorvastatin, PDE5 inhibitors, ergot products, and alfuzosin, as well as others. Drugs that induce CYP3A such as rifampicin and St John's wort should similarly not be used concurrently.

8.6. Boceprevir (BOC). The phase $2 \mathrm{~b}$ SPRINT-1 trial established that a 4-week lead-in with BOC and the inclusion of RBV were necessary for optimal SVR rates [210]. As in the case of TPV, two-phase 3 trials established that BOC was equally effective in Gt1 infected treatment-naïve and treatment-experienced patients $[211,212]$. All patients in the SPRINT-2 trial received a 4-week lead-in of PR and then randomly assigned to receive either $\mathrm{PR} /$ placebo for a further 44 weeks, or PR/BOC $800 \mathrm{mg}$ TID for a further 44 weeks, or $\mathrm{PR} / \mathrm{BOC}$ for a further 24 weeks followed by PR for an extra 20 weeks if HCV RNA was still detectable between weeks 8-24 (RGT). Stopping rules were applied if patients were still HCV RNA positive at week 24. In both BOC arms SVR rates were almost identical, averaging $67.5 \%$ in nonblack patients as opposed to $40 \%$ in the control group. For black patients the figures were $53 \%$ and $42 \%$ for the 48 -week BOC arm and the RGT group, respectively versus $23 \%$ for the controls. A reduction in HCV RNA of $\geq 1$ log during the lead-in period was predictive of SVR in all groups. Relapse rates stood at $8.5 \%$ in the BOC arms versus $23 \%$ in the controls in the case of nonblack patients, whereas in black patients the relapse rate was similar in all groups ranging from $12-17 \%$.

Adverse events necessitated discontinuation of treatment in $12-16 \%$ of patients in all 3 arms of the trial. Anaemia affected $49 \%$ of BOC-treated patients as opposed to $29 \%$ 
of controls, but even though dose reduction secondary to anaemia was more common in the BOC-treated patients (21 versus 13\%), treatment discontinuation was rare (2 versus $1 \%)$. Additionally, dysgeusia was associated with BOC treatment.

The RESPOND-2 trial involved treatment-experienced patients (nonresponders or relapsers), [209] with treatment arms as in SPRINT-2 except for the RGT arm where the leadin was followed by 32 weeks of treble therapy if HCV RNA was undetectable at week 8 or treble therapy for 32 weeks followed by 12 additional weeks of PR if HCV RNA was detectable at week 8 . Treatment was discontinued in patients still positive for HCV RNA at week 12 . SVR rates were $66 \%$ and $59 \%$ for the 44 weeks and RGT groups respectively versus $21 \%$ in controls. SVR was higher in relapsers than nonresponders, and once again a $\geq 1$ log drop in HCV RNA at the end of the lead-in period entailed higher SVR rates at $79 \%$ and $73 \%$ for the 44 weeks and RGT groups, respectively. Even in patients with less than 1 log drop in HCV RNA the chances in the BOC arms of achieving SVR were higher at $33.5 \%$ versus $0 \%$ in controls. Discontinuation due to adverse events was very similar to SPRINT-2.

As with TPV, BOC is a potent inhibitor of CYP3A and therefore contraindicated for use with medications that are also dependent on CYP3A clearance. Also, its use should be avoided with medications that induce CYP3A to prevent loss of efficacy.

8.7. Resistance Associated Variants (RAVs). Monotherapy with TPV or BOC selects preexisting resistant variants from the quasispecies pool within 1-2 weeks of starting treatment [213]. Such variants however are replication less competent. Cross-resistance between TPV and BOC has been reported [214]. Use of RBV appears to be important in minimising resistance at $2 \%$ in treble therapy regimens as opposed to $26 \%$ in RBV free use [200]. After stopping therapy, resistant viruses are overtaken once again by the wild type [214-216]. Amino acid substitutions that confer resistance and cross resistance between TPV and BOC, include R155 K, T54S/A, V36 M, and A156T.

8.8. NS3/4A DAAs in Clinical Testing. As already mentioned a number of other DAAs against the NS3/4A serine protease are at different stages of clinical testing. Simeprevir (TMC435) has shown efficacy when given with PR in both treatment naïve and treatment-experienced patients [217]. In vitro, it is active against all six genotypes, less so though against Gt3a [218, 219]. A side effect of treatment was reversible hyperbilirubinemia. The final results of the ASPIRE trial (phase-IIb) in Gt1 treatment-experienced patients were reported at the 2012 EASL meeting. SVR rates were $85 \%, 75 \%$, and $51 \%$ versus $37 \%, 9 \%$, and $19 \%$ in the $150 \mathrm{mg}$ TMC435 arm versus controls for relapsers, partial, and null responders, respectively [220].

Danoprevir (ITMN191/R7227) is yet another potent macrocyclic PI, which has demonstrated high SVR rates [221]. Patients treated with high doses have experienced grade 4 ALT elevations. Therefore, to increase levels of the drug and restrict liver toxicity, the drug is coadministered with ritonavir and has been shown that in combination with $\mathrm{PR}$ is effective [222].

Other PIs giving promising results in phase-II studies include Asunaprevir (BMS-650032) and BI207127 [223].

8.9. RdRp Inhibitors. Two groups of such inhibitors have been developed so far: nucleoside and nonnucleoside inhibitors (NIs and NNIs). NIs are directed against the active site of the enzyme and are RNA chain terminators. The first such inhibitor to be developed was Valopicitabine which showed weak antiviral activity and was withdrawn due to gastrointestinal problems. More promising chain terminating drugs have since been developed which appear to have a very high genetic barrier to resistance and are active against all genotypes since the RdRp is highly conserved between genotypes [224]. In vitro studies have indicated that for resistance to occur three separate mutations are required [225]. On the other hand, NNIs interfere with RdRp function through binding to four allosteric sites, preventing the polymerase from assuming a functional conformation. NNIs binding to site 1 (thumb 1) include BI207127 and Tegobuvir (GS9190), those binding to site 2 (thumb 2) include Filibuvir (PF-00868554) and VX-222, whilst those binding to sites 3 (palm 1) and 4 (palm 2) include ANA598 and ABT-333, respectively. NNIs have a low resistance barrier and some of them have limited clinical efficacy [224].

In the proton trial of the NI PSI-7977 combined with PR, SVR rates of more than 94\% were reported in Gt1 infected patients, independently of predictors of poor IFN response, and similarly high rates of $96 \%$ in GT2 and 3 [226]. Recently, interim results from the ATOMIC study were reported showing eRVR rates of around $97 \%$ and SVR12 rates above 90\% [227]. Mericitabine (RG7128) in combination with PR leads to high eRVR rates $(>80 \%)$ but treatment with the drug for 8 or 12 weeks gave overall SVR rates not much different than the control arm, but analysing the results according to IL28B CC genotype, SVR rates ranged from 60-91 in the different treatment arms versus 58 in the PR group [228]. Treatment for 24 weeks with mericitabine, appears to be more effective with SVR12 rates of 58\% versus $38 \%$ in the PR group [229].

NNIs have shown significant increases in eRVR rates in phase II studies, but SVR rates have been modest at around $50 \%$ in combination with PR [230]. Such inhibitors though may be useful when used in combination with others as described below.

8.10. NS4B. Clemizole hydrochloride has been shown to interfere with RNA binding to the arginine rich motif at the carboxyl end of the protein [231]. This agent is currently undergoing preclinical evaluation.

8.11. NS5A Inhibitors. The NS5A protein forms part of the viral replication complex, $[232,233]$ interacts with a number of cellular factors [234], and interferes with the innate immune response, [235] but has no enzymatic function. The protein has three domains involved with membrane binding 
(domain I), cyclophilin interaction (domain II) and virus assembly (domain III) [236]. Inhibitors have been identified which act against NS5A functions. One such compound is Daclatasvir (BMS-790052) which in a phase II study has shown high efficacy in treatment naïve Gt1 patients (SVR12 of $83-92 \%$ versus $24 \%$ in PR group), [237] as well as in null responders.

Other NS5A inhibitors include GS5885, ACH-2928, and ABT-267, which in phase I studies have shown strong suppression of HCV RNA and are currently in phase II studies. Preliminary results with ABT-267 in combination with PR for 12 weeks followed by PR for 36 weeks achieved week 4 RVR in $74 \%$ and cEVR (complete early virological response) at week 12 in $87 \%$ of patients compared to $33 \%$ and $67 \%$ in the placebo group [238].

8.12. Quad Treatment. Use of two inhibitors in combination with PR has produced even more dramatic results. A study comparing a combination in treatment naïve Gt 1 patients of a PI (GS-9256) and an NNI (Tegubovir, GS-9190) with or without RBV or PR for 4 weeks, achieved RVR rates of $100 \%$, $38 \%$, and $7 \%$ for the PI/NNI/PR, PI/NNI/RBV, and PI/NNI arms, respectively. Interestingly, the patients receiving quad treatment maintained HCV suppression (week 24), whilst $100 \%$ of treble therapy patients achieved cEVR by week 12 and maintained this response through week 24 [239, 240]. Viral breakthrough due to RAV, was responsible for the poor response in the two test agent arms. The ZENITH trial once again in treatment naïve Gt1 patients, using a combination of a PI (TPV) and an NNI (VX-222) with or without RBV, or with $\mathrm{PR}$, indicated response rates in the $\mathrm{PI} / \mathrm{NNI} / \mathrm{PR}$ treated patients comparable to those seen with TPV/PR, without viral breakthrough. What is more, up to $50 \%$ of patients who had only 12 weeks of therapy achieved SVR12 rates of 82-93\% [241]. Dual therapy failure was associated with viral breakthrough as a result of emergence of RAVs [242].

Quadruple therapy has also been attempted by combining the NS5A inhibitor Daclatasvir (BMS-790052) and the PI Asunaprevir (BMS-650032) with PR for 24 weeks, in Gt1 null responders $[243,244]$. The quadruple combination achieved SVR in all treated patients, whilst the two drug arm showed a $55 \%$ viral breakthrough which affected all Gtla patients and only one of the $1 \mathrm{~b}$ patients.

SVR12 results were recently reported following combination treatment with ABT-450 (PI)/Ritonavir (ABT-450/r) and PR in Gt1 infected patients. The once daily dose arm of 200/100 mg of DAAs for 12 weeks followed by PR for 12-36 weeks yielded the highest SVR12 rate at $88 \%$. 100\% of patients in this arm had attained RVR (week 4), cEVR (HCV RNA undetectable at week 12), and EOT HCV RNA undetectable [245]. Speedy suppression of HCV RNA has also been reported with quadruple combination of Danoprevir/Ritonavir/PR at week 12 in the DAUPHINE trial, with average rates of HCV RNA levels $<15 \mathrm{IU} / \mathrm{mL}$ in all Danopre$\mathrm{vir} / \mathrm{r}$ arms of $89.5 \%$ as opposed to $45 \%$ in the control arm [246]. Finally, a combination of tegubovir, GS-9256 with PR resulted in an SVR rate of $98 \%$ after 16 weeks of treatment [247].
8.13. IFN-Free Regimens. The potent suppression of $\mathrm{HCV}$ RNA in combination treatments with PR raised the possibility of using IFN-free regimens for the treatment of chronic HCV infection, provided that the drugs used had a high genetic barrier to resistance. The first such study combined the NI Sofosbuvir (PSI-7977) and RBV for 12 weeks of therapy in Gt2 and 3 patients and resulted in $100 \%$ SVR12 (and also SVR24 in those that this information was available) [248]. A further trial employing Sofosbuvir and another analogue, PSI-938 led to the dropping of the latter due to hepatotoxicity problems. Dual therapy with Daclatasvir and Asunaprevir for 24 weeks in Gt1 Japanese patients who were either null responders or ineligible for or intolerant to IFN treatment, achieved SVR12 rates of $90 \%$ and 64\%, respectively [249]. Daclatasvir in combination with Sofosbuvir, with or without RBV achieved SVR4 rates of $100 \%$ in Gt1, 91\% in Gt2 and 3, independently of IL28B genotype. RBV did not have any advantage over dual therapy [250].

Treble therapy with the PI BI 201335, the NNI BI 207127, and with or without RBV produced an SVR12 rate of $68 \%$ in previously untreated Gt1 patients versus 38\% in the RBV free combination, with favourable safety and efficacy among people with liver cirrhosis also. Response rates were higher in Gt1b and patients with the IL28B CC genotype. Viral breakthrough was also reported at an average of $11 \%$ between the treble treatment arms versus $29 \%$ in the dual therapy arm [251]. In cirrhotic patients, the treble therapy achieved SVR12 rates of $60 \%$ in Gt1a and $83 \%$ in Gt1b infected patients [252].

Quadruple therapy with ABT-450/r, the NNI ABT-072, and RBV was well tolerated and achieved an SVR24 rate of 91\% in treatment naïve, noncirrhotic Gt1 infected patients with the IL28B CC genotype after 12 weeks of treatment [253]. A combination of GS-5885 (NS5A inhibitor), the NNI tegubovir, the PI GS-9451, and RBV achieved an SVR4 in 95\% of patients treated for 12 weeks. Viral breakthrough and relapse was restricted to Gt1a infected patients [254].

8.14. Host Factor-Targeting Agents. Successful viral replication is dependent on a number of host factors such as cellular receptors, factors involved in replication, and scaffolding proteins involved in viral morphogenesis. Such factors constitute potential targets for antiviral treatment and the chances of viral resistance are quite low.

Moreover, their use in combination with DAAs would theoretically reduce the dependence on IFN containing treatment regimens. However, some of these factors may be essential for normal host function and there may well be potential adverse effects.

8.14.1. Cyclophilin Inhibitors. Cyclophilins are essential for viral replication, being part of the replication complex through interaction with NS5A [255]. Cyclosporine is an effective inhibitor of cyclophilins, but in view of its immunosuppressive effects through inhibition of calcineurin, cannot be used for treatment purposes. Nonimmunosuppressive alternatives have been developed such as Alisporivir 
(DEBIO 025) and SCY-635 [256, 257]. Alisporivir has shown broad genotype potency and selection of resistant variants has proved difficult [258]. Alisporivir in combination with PR in Gt1 patients achieved $76 \%$ SVR compared with $55 \%$ in the PR arm [259]. However, an ongoing trial had to be halted recently due to a number of pancreatitis cases, including one death.

8.14.2. MiR-122 Inhibitors. MicroRNAs are endogenous noncoding RNAs that are involved in regulation of gene expression by interfering with the translation and stability of target mRNAs. MiR-122 is a liver specific microRNA involved in HCV RNA replication [260]. Miravirsen (SPC3649) is a locked nucleic acid modified phosphorothioate antisense oligonucleotide complementary to the MiR-122 seed sequences [261]. The drug sequesters MiR-122 preventing it from binding to the $5^{\prime}$ UTR of HCV RNA and leads to longlasting suppression of viraemia with no emergence of RAVs in chimpanzee studies [261]. Similar results have been reported in patients treated with weekly SC injections for 29 days, and followed up for 18 weeks [262].

8.14.3. Entry Inhibitors. ITX-5061 is the first in class HCV entery inhibitor targeted against SR-B1 which is in clinical development [263]. Another potential entry inhibitor is Ezetimibe [175].

8.15. Conclusion. Antiviral treatment against chronic HCV infection has come a long way since the introduction of standard IFN as monotherapy. Over the years through the licensing of PegIFN in combination with RBV, and more recently the addition of PIs in treble treatment regimens has seen an increase in SVR rates well above $80 \%$ in difficult to treat patients such as those infected with Gt1. The future looks bright with the potential of using IFN sparing cocktails of DAAs able to achieve extremely high SVR rates. The success of such cocktails will be dependent on their ability to act pangenotypically, to prevent emergence of resistance, and to be adverse event free.

\section{Hepatitis D Virus (HDV)}

HDV is a defective RNA virus, more closely related to plant viroids than other human viruses, and dependent on $\mathrm{HBV}$ for its outer HBsAg containing envelope. In this respect, HDV infection can occur following exposure to both viruses concurrently (coinfection) or following exposure of somebody who is already a chronic HBV carrier (superinfection) [264]. In the latter case, there is increased likelihood of HDV infection becoming chronic also. Clinical disease in this scenario can be variable running either a benign course or causing severe liver disease which is more likely, with rapid progression to cirrhosis and HCC [265-267].

9.1. Virology. The HDV particle has a diameter of $36 \mathrm{~nm}$ and consists of an outer envelope containing all 3 forms of HBsAg. This surrounds the capsid which consists of hepatitis $\mathrm{D}$ antigen (HDAg) [268] and encloses the single stranded, circular RNA genome of the virus, which is of negative sense and approximately $1700 \mathrm{nt}$ in length. The genome forms an unbranched rod-like structure due to intramolecular basepairing that implicates more than $70 \%$ of its nucleotide sequence [269]. Unique features of this RNA are the presence of only one ORF which encodes the HDAg, the absence of a viral RNA polymerase and the presence of an RNA fold formed by about $85 \mathrm{nts}$, which acts as a ribozyme and is so essential during virus replication as explained below [270].

9.2. Replication. The virus possibly utilises the same cellular receptor as $\mathrm{HBV}$ due to their common $\mathrm{HBsAg}$ containing envelope. Uncoating occurs in the cytoplasm of the hepatocyte and the HDAg core is transferred to the nuclear pore, followed by delivery of the HDV RNA to the nucleoplasm. RNA transcription leads to the formation of a full length antigenomic strand which circularises and constitutes the template for genome synthesis, and of a subgenomic $(0.8 \mathrm{~kb})$, polyadenylated mRNA that encodes for HDAg. RNA synthesis occurs in the nucleus and implicates the nucleolus in antigenomic strand synthesis through the use of RNA polymerase I, whilst genomic strand synthesis occurs in the nucleoplasm and utilsises RNA polymerase II [271]. During RNA synthesis, both the genomic and antigenomic templates are employed in a rolling circle mechanism to produce concatemers of multiple full length RNA copies, which are cleaved by the ribozyme fold present in both forms of RNA to unit lengths, which then circularize [272]. There are two forms of HDAg which are known as small (SHDAg, 195aa long) and large (L-HDAg, 214a long). These are encoded by the subgenomic mRNA, [273] and the LHDAg arises through an RNA editing event that involves adenosine deaminase- 1 that converts the termination codon for the S-HDAg to one for tryptophan. Thus, the L-HDAg has an extension of 19 further aa [269, 273]. The two forms of HDAg have unique functions in that the S-HDAg promotes replication whilst the L-HDAg suppresses replication and promotes viral morphogenesis [274].

9.3. Treatment. Treatment regimens for chronic HDV should target the helper HBV also for optimal results. Standard and recombinant interferons were thus first used for the treatment of chronic HDV infection but proved disappointing, in that after 12 months of treatment virologic responses were largely not sustainable $[275,276]$. More recent use of PegIFN has produced variable SVR rates (17-43\%) which are defined as negative HDV-RNA 6 months after cessation of treatment. The number of patients included in such trials was relatively small compared to the numbers enrolled in similar HBV and HCV trials and SVR rates may have been affected by heterogeneous baseline clinical, demographic, and virological parameters. PegIFN monotherapy has attained SVR rates of $17-25 \%,[277,278]$ with the exception of one trial involving 14 patients which reported an SVR rate of 43\% [279]. Addition of RBV to the treatment regimen had no additive effect $[277,280]$. Similarly, PegIFN in combination with LMV or ADV did not increase SVR rates, whilst monotherapy with 
either LMV or ADV achieved SVR rates of $12 \%$, and $0 \%$ respectively [281, 282].

Treatment regimens which suppress HBV DNA, although desirable, are unlikely to effect HDV clearance as HBsAg may still be provided by integrated HBV DNA sequences. HBsAg clearance has proved a difficult endpoint to achieve following antiviral treatment. Novel treatments targeting HDV replication are restricted as a result of the limited coding capacity of the genome to just one protein, namely, HDAg, and the complete absence of virally encoded enzymes. However, HDAg undergoes posttranslational modification through acetylation, methylation, and phosphorylation for optimal function. Interference with these processes is possible and may undermine virus replication. Indeed prenylation of the L-HDAg is essential for viral assembly and secretion [283]. Prenylation inhibitors have been shown to be effective in clearing HDV RNA in a mouse model [284]. With evidence from epidemiological studies that HDV prevalence remains unchanged, and in fact is some European countries may be on the increase as a result of immigration, there should be renewed efforts for novel drug development.

\section{References}

[1] W. M. Lee, "Hepatitis B virus infection," New England Journal of Medicine, vol. 337, no. 24, pp. 1733-1745, 1997.

[2] "Global surveillance and control of hepatitis C," Journal of Viral Hepatitis, vol. 6, no. 1, pp. 35-47, 1999.

[3] T. M. Block, H. Guo, and J. T. Guo, "Molecular Virology of Hepatitis B Virus for Clinicians," Clinics in Liver Disease, vol. 11, no. 4, pp. 685-706, 2007.

[4] J. F. Perz, G. L. Armstrong, L. A. Farrington, Y. J. F. Hutin, and B. P. Bell, "The contributions of hepatitis B virus and hepatitis $C$ virus infections to cirrhosis and primary liver cancer worldwide," Journal of Hepatology, vol. 45, no. 4, pp. 529-538, 2006.

[5] A. Hatzakis, S. Wait, J. Bruix et al., "The state of hepatitis B and $C$ in Europe: report from the hepatitis B and C summit conference," Journal of Viral Hepatitis, vol. 18, supplement 1, pp. 1-16, 2011.

[6] C. Seeger and W. S. Mason, "Hepatitis B virus biology," Microbiology and Molecular Biology Reviews, vol. 64, no. 1, pp. 51-68, 2000.

[7] D. Ganem and R. J. Schneider, "Hepadnaviridae: the viruses and their replication," in Fields Virology, D. M. Knipe, D. E. Griffin, R. A. Lamb, M. A. Martin, B. Roizman, and S. E. Straus, Eds., pp. 2923-2969, Lippincott Williams \& Wilkins, Philadelphia, 4th edition, 2001.

[8] H. Norder, A. M. Courouce, and L. O. Magnius, "Molecular basis of hepatitis B virus serotype variations within the four major subtypes," Journal of General Virology, vol. 73, no. 12, pp. 3141-3145, 1992.

[9] H. Norder, A. M. Courouce, and L. O. Magnius, "Complete genomes, phylogenetic relatedness, and structural proteins of six strains of the hepatitis B virus, four of which represent two new genotypes," Virology, vol. 198, no. 1, pp. 489-503, 1994.

[10] M. Lindh, A. S. Andersson, and A. Gusdal, "Genotypes, nt 1858 variants, and geographic origin of hepatitis B virus-large-scale analysis using a new genotyping method," Journal of Infectious Diseases, vol. 175, no. 6, pp. 1285-1293, 1997.
[11] H. Naumann, S. Schaefer, C. F. T. Yoshida, A. M. C. Gaspar, R. Repp, and W. H. Gerlich, "Identification of a new hepatitis B virus (HBV) genotype from Brazil that expresses HBV surface antigen subtype adw4," Journal of General Virology, vol. 74, no. 8, pp. 1627-1632, 1993.

[12] C. J. Chu, E. B. Keeffe, S. H. Han et al., "Hepatitis B virus genotypes in the United States: results of a nationwide study," Gastroenterology, vol. 125, no. 2, pp. 444-451, 2003.

[13] M. Nassal, "Hepatitis B viruses: reverse transcription a different way," Virus Research, vol. 134, no. 1-2, pp. 235-249, 2008.

[14] A. R. Neurath, S. B. H. Kent, N. Strick, and K. Parker, "Identification and chemical synthesis of a host cell receptor binding site on hepatitis B virus," Cell, vol. 46, no. 3, pp. 429-436, 1986.

[15] A. R. Neurath, B. Seto, and N. Strick, "Antibodies to synthetic peptides from the preS1 region of the hepatitis B virus (HBV) envelope (env) protein are virus-neutralizing and protective," Vaccine, vol. 7, no. 3, pp. 234-236, 1989.

[16] N. Paran, B. Geiger, and Y. Shaul, "HBV infection of cell culture: evidence for multivalent and cooperative attachment," EMBO Journal, vol. 20, no. 16, pp. 4443-4453, 2001.

[17] J. S. Tuttleman, C. Pourcel, and J. Summers, "Formation of the pool of covalently closed circular viral DNA in hepadnavirusinfected cells," Cell, vol. 47, no. 3, pp. 451-460, 1986.

[18] S. Locarnini and C. Birch, "Antiviral chemotherapy for chronic hepatitis B infection: lessons learned from treating HIVinfected patients," Journal of Hepatology, vol. 30, no. 3, pp. 536-550, 1999.

[19] J. Summers and W. S. Mason, "Replication of the genome of a hepatitis B-like virus by reverse transcription of an RNA intermediate," Cell, vol. 29, no. 2, pp. 403-415, 1982.

[20] A. Kramvis and M. C. Kew, "Structure and function of the encapsidation signal of hepadnaviridae," Journal of Viral Hepatitis, vol. 5, no. 6, pp. 357-367, 1998.

[21] M. Nassal and H. Schaller, "Hepatitis B virus replication-an update," Journal of Viral Hepatitis, vol. 3, no. 5, pp. 217-226, 1996.

[22] F. Zoulim and C. Seeger, "Reverse transcription in hepatitis B viruses is primed by a tyrosine residue of the polymerase," Journal of Virology, vol. 68, no. 1, pp. 6-13, 1994.

[23] M. Weber, V. Bronsema, H. Bartos, A. Bosserhoff, R. Bartenschlager, and $\mathrm{H}$. Schaller, "Hepadnavirus $\mathrm{P}$ protein utilizes a tyrosine residue in the TP domain to prime reverse transcription," Journal of Virology, vol. 68, no. 5, pp. 2994-2999, 1994.

[24] R. A. Crowther, N. A. Kiselev, B. Bottcher et al., "Threedimensional structure of hepatitis B virus core particles determined by electron cryomicroscopy," Cell, vol. 77, no. 6, pp. 943-950, 1994.

[25] T. Gerelsaikhan, J. E. Tavis, and V. Bruss, "Hepatitis B virus nucleocapsid envelopment does not occur without genomic DNA synthesis," Journal of Virology, vol. 70, no. 7, pp. 4269-4274, 1996.

[26] L. O. Magnius and H. Norder, "Subtypes, genotypes and molecular epidemiology of the hepatitis B virus as reflected by sequence variability of the S-gene," Intervirology, vol. 38, no. 12, pp. 24-34, 1995.

[27] L. Mimms, "Hepatitis B virus escape mutants: 'pushing the envelope' of chronic hepatitis B virus infection," Hepatology, vol. 21, no. 3, pp. 884-887, 1995.

[28] W. F. Carman, M. R. Jacyna, S. Hadziyannis et al., "Mutation preventing formation of hepatitis $\mathrm{B}$ e antigen in patients with chronic hepatitis B infection," Lancet, vol. 2, no. 8663, pp. 588-591, 1989. 
[29] M. R. Brunetto, M. Stemler, F. Schodel et al., "Identification of HBV variants which cannot produce precore derived $\mathrm{HBeAg}$ and may be responsible for severe hepatitis," Italian Journal of Gastroenterology, vol. 21, no. 3, pp. 151-154, 1989.

[30] P. P. Scaglioni, M. Melegari, and J. R. Wands, "Biologic properties of hepatitis B viral genomes with mutations in the precore promoter and precore open reading frame," Virology, vol. 233, no. 2, pp. 374-381, 1997.

[31] H. Okamoto, F. Tsuda, Y. Akahane et al., "Hepatitis B virus with mutations in the core promoter for an e antigen- negative phenotype in carriers with antibody to e antigen," Journal of Virology, vol. 68, no. 12, pp. 8102-8110, 1994.

[32] V. E. Buckwold, Z. Xu, M. Chen, T. S. B. Yen, and J. H. Ou, "Effects of a naturally occurring mutation in the hepatitis $\mathrm{B}$ virus basal core promoter on precore gene expression and viral replication," Journal of Virology, vol. 70, no. 9, pp. 5845-5851, 1996.

[33] P. Karayiannis, M. J. F. Fowler, and A. S. F. Lok, "Detection of serum HBV-DNA by molecular hybridisation. Correlation with $\mathrm{HBeAg}$ /anti-HBe status, racial origin, liver histology and hepatocellular carcinoma," Journal of Hepatology, vol. 1, no. 2, pp. 99-106, 1985.

[34] S. Hadziyannis, "Hepatitis B e antigen negative chronic hepatitis B: from clinical recognition to pathogenesis and treatment," Viral Hepatitis Reviews, vol. 1, pp. 7-36, 1985.

[35] J. P. Zarski, P. Marcellin, M. Cohard, J. M. Lutz, C. Bouche, and A. Rais, "Comparison of anti-HBe-positive and HBe-antigenpositive chronic hepatitis B in France," Journal of Hepatology, vol. 20, no. 5, pp. 636-640, 1994.

[36] M. R. Brunetto, M. M. Giarin, F. Oliveri et al., "Wild-type and e antigen-minus hepatitis B viruses and course of chronic hepatitis," Proceedings of the National Academy of Sciences of the United States of America, vol. 88, no. 10, pp. 4186-4190, 1991.

[37] H. S. Margolis, M. J. Alter, and S. C. Hadler, "Hepatitis B: evolving epidemiology and implications for control," Seminars in Liver Disease, vol. 11, no. 2, pp. 84-92, 1991.

[38] P. Coursaget, B. Yvonnet, and J. Chotard, "Age- and sex-related study of hepatitis B virus chronic carrier state in infants from an endemic area (Senegal)," Journal of Medical Virology, vol. 22, no. 1, pp. 1-5, 1987.

[39] B. J. McMahon, W. L. M. Alward, and D. B. Hall, "Acute hepatitis B virus infection: relation of age to the clinical expression of disease and subsequent development of the carrier state," Journal of Infectious Diseases, vol. 151, no. 4, pp. 599-603, 1985.

[40] N. C. Tassopoulos, G. J. Papaevangelou, and M. H. Sjogren, "Natural history of acute hepatitis B surface antigen-positive hepatitis in Greek adults," Gastroenterology, vol. 92, no. 6, pp. 1844-1850, 1987.

[41] A. A. Evans and W. T. London, "Epidemiology of hepatitis B," in Viral Hepatitis, A. J. Zuckerman and H. C. Thomas, Eds., pp. 107-114, Churchill livingstone, London, UK, 1998.

[42] S. J. Hadziyannis and G. V. Papatheodoridis, "Hepatitis B e antigen-negative chronic hepatitis B: natural history and treatment," Seminars in Liver Disease, vol. 26, no. 2, pp. 130-141, 2006.

[43] C. L. Lai, H. J. Lin, E. K. Yeoh, A. S. F. Lok, P. C. Wu, and C. Y. Yeung, "Placebo-controlled trial of recombinant $\alpha 2$-interferon in Chinese HBsAg-carrier children," Lancet, vol. 2, no. 8564, pp. 877-880, 1987.
[44] A. S. F. Lok, C. L. Lai, P. C. Wu et al., "Treatment of chronic hepatitis B with interferon: experience in Asian patients," Seminars in Liver Disease, vol. 9, no. 4, pp. 249-253, 1989.

[45] T. Nguyen, P. Desmond, and S. Locarnini, "The role of quantitative hepatitis B serology in the natural history and management of chronic hepatitis B," Hepatology International, supplement 1, pp. 5-15, 2009.

[46] J. Jaroszewicz, B. C. Serrano, K. Wursthorn et al., "Hepatitis B surface antigen ( $\mathrm{HBsAg}$ ) levels in the natural history of hepatitis B virus (HBV)-infection: a European perspective," Journal of Hepatology, vol. 52, no. 4, pp. 514-522, 2010.

[47] R. P. Perrillo, "Treatment of chronic hepatitis B with interferon: experience in western countries," Seminars in Liver Disease, vol. 9, no. 4, pp. 240-248, 1989.

[48] P. Karayiannis, "Serum HBsAg levels and their utility as a predictor of sustained virological response after antiviral treatment," Hepatitis Monthly, vol. 12, no. 7, pp. 420-422, 2012.

[49] G. Fattovich, F. Bortolotti, and D. Francesco, "Natural history of chronic hepatitis B: special emphasis on disease progression and prognostic factors," Journal of Hepatology, vol. 48, no. 2, pp. 335-352, 2008.

[50] G. K. K. Lau, T. Piratvisuth, X. L. Kang et al., "Peginterferon Alfa-2a, lamivudine, and the combination for $\mathrm{HBeAg}$-positive chronic hepatitis B," New England Journal of Medicine, vol. 352, no. 26, pp. 2682-2695, 2005.

[51] P. Marcellin, G. K. K. Lau, F. Bonino et al., "Peginterferon Alfa-2a alone, lamivudine alone, and the two in combination in patients with $\mathrm{HBeAg}$-negative chronic hepatitis B," New England Journal of Medicine, vol. 351, no. 12, pp. 1206-1217, 2004.

[52] H. L. A. Janssen, M. Van Zonneveld, H. Senturk et al., "Pegylated interferon alfa- $2 \mathrm{~b}$ alone or in combination with lamivudine for HBeAg-positive chronic hepatitis B: a randomised trial," Lancet, vol. 365, no. 9454, pp. 123-129, 2005.

[53] H. L. Y. Chan, N. W. Y. Leung, A. Y. Hui et al., "A randomized, controlled trial of combination therapy for chronic hepatitis B: comparing pegylated interferon- $\alpha 2 \mathrm{~b}$ and lamivudine with lamivudine alone," Annals of Internal Medicine, vol. 142, no. 4, pp. 240-250, 2005.

[54] E. H. C. J. Buster, H. J. Flink, Y. Cakaloglu et al., "Sustained $\mathrm{HBeAg}$ and HBsAg loss after long-term follow-up of HBeAgpositive patients treated with peginterferon $\alpha-2 b$," Gastroenterology, vol. 135, no. 2, pp. 459-467, 2008.

[55] P. Marcellin, F. Bonino, G. K. K. Lau et al., "Sustained response of hepatitis $\mathrm{B}$ e antigen-negative patients 3 years after treatment with peginterferon Alfa-2a," Gastroenterology, vol. 136, no. 7, pp. 2169-2179, 2009.

[56] N. C. Tassopoulos, R. Volpes, G. Pasture et al., "Efficacy of lamivudine in patients with hepatitis $B$ e antigen- negative/hepatitis B virus DNA-positive (precore mutant) chronic hepatitis B," Hepatology, vol. 29, no. 3, pp. 889-896, 1999.

[57] F. Bonino, P. Marcellin, G. K. K. Lau et al., "Predicting response to peginterferon $\alpha-2 \mathrm{a}$, lamivudine and the two combined for HBeAg-negative chronic hepatitis B," Gut, vol. 56, no. 5, pp. 699-705, 2007.

[58] R. Moucari, V. Mackiewicz, O. Lada et al., "Early serum HBsAg drop: a strong predictor of sustained virological response to pegylated interferon alfa-2a in $\mathrm{HBeAg}$-negative patients," Hepatology, vol. 49, no. 4, pp. 1151-1157, 2009.

[59] M. R. Brunetto, F. Moriconi, F. Bonino et al., "Hepatitis B virus surface antigen levels: a guide to sustained response to 
peginterferon alfa-2a in HBeAg-negative chronic hepatitis B," Hepatology, vol. 49, no. 4, pp. 1141-1150, 2009.

[60] G. Moraleda, J. Saputelli, C. E. Aldrich, D. Averett, L. Condreay, and W. S. Mason, "Lack of effect of antiviral therapy in nondividing hepatocyte cultures on the closed circular DNA of woodchuck hepatitis virus," Journal of Virology, vol. 71, no. 12, pp. 9392-9399, 1997.

[61] N. Cammack, P. Rouse, C. L. P. Marr et al., "Cellular metabolism of (-) enantiomeric 2 -deoxy- $3^{\prime}$-thiacytidine," Biochemical Pharmacology, vol. 43, no. 10, pp. 2059-2064, 1992.

[62] C. N. Chang, V. Skalski, J. H. Zhou, and Y. C. Cheng, "Biochemical pharmacology of (+)- and (-)-2', $3^{\prime}$-dideoxy$3^{\prime}$-thiacytidine as anti-hepatitis B virus agents," Journal of Biological Chemistry, vol. 267, no. 31, pp. 22414-22420, 1992.

[63] S. L. Doong, C. H. Tsai, R. F. Schinazi, D. C. Liotta, and Y. C. Cheng, "Inhibition of the replication of hepatitis B virus in vitro by $2^{\prime}, 3^{\prime}$-dideoxy- $3^{\prime}$-thiacytidine and related analogues," Proceedings of the National Academy of Sciences of the United States of America, vol. 88, no. 19, pp. 8495-8499, 1991.

[64] A. S.-F. Lok, M. Hussain, C. Cursano et al., "Evolution of hepatitis $\mathrm{B}$ virus polymerase gene mutations in hepatitis $\mathrm{B}$ e antigennegative patients receiving lamivudine therapy," Hepatology, vol. 32, no. 5, pp. 1145-1153, 2000.

[65] S. W. Cho, K. B. Hahm, and J. H. Kim, "Reversion from precore/core promoter mutants to wild-type hepatitis B virus during the course of lamivudine therapy," Hepatology, vol. 32, no. 5, pp. 1163-1169, 2000.

[66] F. Zoulim and C. Trépo, "Is lamivudine effective on precore/core promoter mutants of hepatitis B virus?" Hepatology, vol. 32, no. 5, pp. 1172-1174, 2000.

[67] R. Y. M. Chen, R. Edwards, T. Shaw et al., "Effect of the G1896A precore mutation on drug sensitivity and replication yield of lamivudineresistant HBV in vitro," Hepatology, vol. 37, no. 1, pp. 27-35, 2003.

[68] J. L. Dienstag, E. R. Schiff, T. L. Wright et al., "Lamivudine as initial treatment for chronic hepatitis B in the United States," New England Journal of Medicine, vol. 341, no. 17, pp. 1256-1263, 1999.

[69] C. L. Lai, R. N. Chien, N. W. Y. Leung et al., "A one-year trial of lamivudine for chronic hepatitis B," New England Journal of Medicine, vol. 339, no. 2, pp. 61-68, 1998.

[70] S. W. Schalm, D. F. Gray, J. Heathcote et al., "Lamivudine and alpha interferon combination treatment of patients with chronic hepatitis B infection: a randomised trial," Gut, vol. 46, no. 4, pp. 562-568, 2000.

[71] Y. F. Liaw, N. W. Y. Leung, T. T. Chang et al., "Effects of extended lamivudine therapy in asian patients with chronic hepatitis B," Gastroenterology, vol. 119, no. 1, pp. 172-180, 2000.

[72] N. W. Y. Leung, C. L. Lai, T. T. Chang et al., "Extended lamivudine treatment in patients with chronic hepatitis $\mathrm{B}$ enhances hepatitis B e antigen seroconversion rates: results after 3 years of therapy," Hepatology, vol. 33, no. 6, pp. 1527-1532, 2001.

[73] J. G. P. Reijnders, M. J. Perquin, N. Zhang, B. E. Hansen, and H. L. A. Janssen, "Nucleos(t)ide analogues only induce temporary hepatitis B e antigen seroconversion in most patients with chronic hepatitis B," Gastroenterology, vol. 139, no. 2, pp. 491-498, 2010.

[74] B. C. Song, D. J. Suh, H. C. Lee, Y. H. Chung, and Y. S. Lee, "Hepatitis B e antigen seroconversion after lamivudine therapy is not durable in patients with chronic hepatitis B in Korea," Hepatology, vol. 32, no. 4, pp. 803-806, 2000.
[75] A. S. F. Lok, "The maze of treatments for hepatitis B," New England Journal of Medicine, vol. 352, no. 26, pp. 2743-2746, 2005.

[76] E. B. Keeffe, D. T. Dieterich, S. H. B. Han et al., "A Treatment algorithm for the management of chronic hepatitis B virus infection in the United States: 2008 Update," Clinical Gastroenterology and Hepatology, vol. 6, no. 12, pp. 1315-1341, 2008.

[77] M. Rizzetto, "Efficacy of lamivudine in HBeAg-negative chronic hepatitis B," Journal of Medical Virology, vol. 66, no. 4, pp. 435-451, 2002.

[78] T. Santantonio, M. Mazzola, T. Iacovazzi, A. Miglietta, A. Guastadisegni, and G. Pastore, "Long-term follow-up of patients with anti-HBe/HBV DNA-positive chronic hepatitis B treated for 12 months with lamivudine," Journal of Hepatology, vol. 32, no. 2, pp. 300-306, 2000.

[79] S. J. Hadziyannis, G. V. Papatheodoridis, E. Dimou, A. Laras, and C. Papaioannou, "Efficacy of long-term lamivudine monotherapy in patients with hepatitis B e antigen-negative chronic hepatitis B," Hepatology, vol. 32, no. 4 I, pp. 847-851, 2000.

[80] D. T. Lau, M. Farooq Khokhar, E. Doo et al., "Long-term therapy of chronic hepatitis B with lamivudine," Hepatology, vol. 32, no. 4 I, pp. 828-834, 2000.

[81] M. Rizzetto, R. Volpes, and A. Smedile, "Response of pre-core mutant chronic hepatitis B infection to lamivudine," Journal of Medical Virology, vol. 61, no. 3, pp. 398-402, 2000.

[82] G. V. Papatheodoridis, E. Dimou, A. Laras, V. Papadimitropoulos, and S. J. Hadziyannis, "Course of virologic breakthroughs under long-term lamivudine in $\mathrm{HBeAg-negative} \mathrm{pre-}$ core mutant HBV liver disease," Hepatology, vol. 36, no. 1, pp. 219-226, 2002.

[83] G. Scotto, V. Fazio, F. Campanozzi, and A. D’Adduzio, "Efficacy of treatment with lamivudine in patients with chronic active e- minus variant hepatitis B virus infection: a nonrandomized, open-label study," Current Therapeutic Research, vol. 61, no. 6, pp. 321-330, 2000.

[84] Y. Suzuki, H. Kumada, K. Ikeda et al., "Histological changes in liver biopsies after one year of lamivudine treatment in patients with chronic hepatitis B infection," Journal of Hepatology, vol. 30, no. 5, pp. 743-748, 1999.

[85] Y.-O. Kweon, Z. D. Goodman, J. L. Dienstag et al., "Decreasing fibrogenesis: an immunohistochemical study of paired liver biopsies following lamivudine therapy for chronic hepatitis B," Journal of Hepatology, vol. 35, no. 6, pp. 749-755, 2001.

[86] Y. F. Liaw, J. J. Sung, W. C. Chow et al., "Lamivudine for patients with chronic hepatitis B and advanced liver disease," The New England Journal of Medicine, vol. 351, pp. 1521-1531, 2004.

[87] M. F. Yuen, W. K. Seto, D. H. F. Chow et al., "Long-term lamivudine therapy reduces the risk of long-term complications of chronic hepatitis B infection even in patients without advanced disease," Antiviral Therapy, vol. 12, no. 8, pp. 1295-1303, 2007.

[88] M. Buti, M. Cotrina, R. Jardi et al., "Two years of lamivudine therapy in anti-HBe-positive patients with chronic hepatitis B," Journal of Viral Hepatitis, vol. 8, no. 4, pp. 270-275, 2001.

[89] R. N. Chien, Y. F. Liaw, and M. Atkins, "Pretherapy alanine transaminase level as a determinant for hepatitis B e antigen seroconversion during lamivudine therapy in patients with chronic hepatitis B," Hepatology, vol. 30, no. 3, pp. 770-774, 1999.

[90] R. P. Perrillo, S. W. Schalm, E. R. Schiff et al., "Predictors of HBsAg seroconversion in chronic hepatitis B patients treated with lamivudine," Hepatology, vol. 30, article 317A, 1999. 
[91] Y. F. Liaw, R. N. Chien, C. T. Yeh, S. L. Tsai, and C. M. $\mathrm{Chu}$, "Acute exacerbation and hepatitis $\mathrm{B}$ virus clearance after emergence of YMDD motif mutation during lamivudine therapy," Hepatology, vol. 30, no. 2, pp. 567-572, 1999.

[92] M. M. Bartholomew, R. W. Jansen, L. J. Jeffers et al., "Hepatitis$\mathrm{B}$-virus resistance to lamivudine given for recurrent infection after orthotopic liver transplantation," Lancet, vol. 349, no. 9044, pp. 20-22, 1997.

[93] O. Poch, I. Sauvaget, M. Delarue, and N. Tordo, "Identification of four conserved motifs among the RNA-dependent polymerase encoding elements," EMBO Journal, vol. 8, no. 12, pp. 3867-3874, 1989.

[94] M. I. Allen, M. Deslauriers, C. Webster Andrews et al., "Identification and characterization of mutations in hepatitis B virus resistant to lamivudine," Hepatology, vol. 27, no. 6, pp. 1670-1677, 1998.

[95] K. P. Fischer and D. L. J. Tyrrell, "Generation of duck hepatitis $B$ virus polymerase mutants through site- directed mutagenesis which demonstrate resistance to lamivudine $\left[(-)-\beta-\mathrm{L}-2^{\prime}, 3^{\prime}\right.$ dideoxy-3'-thiacytidine] in vitro," Antimicrobial Agents and Chemotherapy, vol. 40, no. 8, pp. 1957-1960, 1996.

[96] K. Chayama, Y. Suzuki, M. Kobayashi et al., "Emergence and takeover of YMDD motif mutant hepatitis B virus during longterm lamivudine therapy and re-takeover by wild type after cessation of therapy," Hepatology, vol. 27, no. 6, pp. 1711-1716, 1998.

[97] P. Honkoop, H. G. M. Niesters, R. A. M. De Man, A. D. M. E. Osterhaus, and S. W. Schalm, "Lamivudine resistance in immunocompetent chronic hepatitis B. Incidence and patterns," Journal of Hepatology, vol. 26, no. 6, pp. 1393-1395, 1997.

[98] R. Ling, D. Mutimer, M. Ahmed et al., "Selection of mutations in the hepatitis B virus polymerase during therapy of transplant recipients with lamivudine," Hepatology, vol. 24, no. 3, pp. 711-713, 1996.

[99] G. A. Tipples, M. M. Ma, K. P. Fischer, V. G. Bain, N. M. Kneteman, and D. L. J. Tyrrell, "Mutation in HBV RNAdependent DNA polymerase confers resistance to lamivudine in vivo," Hepatology, vol. 24, no. 3, pp. 714-717, 1996.

[100] H. G. M. Niesters, P. Honkoop, E. B. Haagsma, R. A. De Man, S. W. Schalm, and A. D. M. E. Osterhaus, "Identification of more than one mutation in the hepatitis B virus polymerase gene arising during prolonged lamivudine treatment," Journal of Infectious Diseases, vol. 177, no. 5, pp. 1382-1385, 1998.

[101] M. Melegari, P. P. Scaglioni, and J. R. Wands, "Hepatitis B virus mutants associated with 3TC and Famciclovir administration are replication defective," Hepatology, vol. 27, no. 2, pp. 628-633, 1998.

[102] S. K. Ono, N. Kato, Y. Shiratori et al., "The polymerase L528M mutation cooperates with nucleotide binding-site mutations, increasing hepatitis B virus replication and drug resistance," Journal of Clinical Investigation, vol. 107, no. 4, pp. 449-455, 2001.

[103] T. T. Aye, A. Bartholomeusz, T. Shaw et al., "Hepatitis B virus polymerase mutations during antiviral therapy in a patient following liver transplantation," Journal of Hepatology, vol. 26, no. 5, pp. 1148-1153, 1997.

[104] H. L. Tillmann, C. Trautwein, T. Bock et al., "Mutational pattern of hepatitis B virus on sequential therapy with famciclovir and lamivudine in patients with hepatitis B virus reinfection occurring under HBIg immunoglobulin after liver transplantation," Hepatology, vol. 30, no. 1, pp. 244-256, 1999.
[105] C. T. Yeh, R. N. Chien, C. M. Chu, and Y. F. Liaw, "Clearance of the original hepatitis $\mathrm{B}$ virus YMDD-motif mutants with emergence of distinct lamivudine-resistant mutants during prolonged lamivudine therapy," Hepatology, vol. 31, no. 6, pp. 1318-1326, 2000.

[106] S. Villet, C. Pichoud, G. Billioud et al., "Impact of hepatitis B virus rtA181V/T mutants on hepatitis B treatment failure," Journal of Hepatology, vol. 48, no. 5, pp. 747-755, 2008.

[107] R. A. Heijtink, G. A. De Wilde, J. Kruining et al., "Inhibitory effect of 9-(2-phosphonylmethoxyethyl)-adenine (PMEA) on human and duck hepatitis B virus infection," Antiviral Research, vol. 21, no. 2, pp. 141-153, 1993.

[108] A. J. Nicoll, D. L. Colledge, J. J. Toole, P. W. Angus, R. A. Smallwood, and S. A. Locarnini, "Inhibition of duck hepatitis B virus replication by 9-(2- phosphonylmethoxyethyl)adenine, an acyclic phosphonate nucleoside analogue," Antimicrobial Agents and Chemotherapy, vol. 42, no. 12, pp. 3130-3135, 1998.

[109] X. Xiong, C. Flores, H. Yang, J. J. Toole, and C. S. Gibbs, "Mutations in hepatitis B DNA polymerase associated with resistance to lamivudine do not confer resistance to adefovir in vitro," Hepatology, vol. 28, no. 6, pp. 1669-1673, 1998.

[110] R. Perrillo, E. Schiff, E. Yoshida et al., "Adefovir dipivoxil for the treatment of lamivudine-resistant hepatitis B mutants," Hepatology, vol. 32, no. 1, pp. 129-134, 2000.

[111] R. J. C. Gilson, K. B. Chopra, A. M. Newell et al., "A placebocontrolled phase I/II study of adefovir dipivoxil in patients with chronic hepatitis B virus infection," Journal of Viral Hepatitis, vol. 6, no. 5, pp. 387-395, 1999.

[112] M. Tsiang, J. F. Rooney, J. J. Toole, and C. S. Gibbs, "Biphasic clearance kinetics of hepatitis B virus from patients during adefovir dipivoxil therapy," Hepatology, vol. 29, no. 6, pp. 1863-1869, 1999.

[113] M. G. Peters, G. Singer, T. Howard et al., "Fulminant hepatic failure resulting from lamivudine- resistant hepatitis B virus in a renal transplant recipient: durable response after orthotopic liver transplantation on adefovir dipivoxil and hepatitis B immune globulin," Transplantation, vol. 68, no. 12, pp. 1912-1914, 1999.

[114] Y. Benhamou, M. Bochet, V. Thibault et al., "Safety and efficacy of adefovir dipivoxil in patients co-infected with HIV-1 and lamivudine-resistant hepatitis B virus: an open-label pilot study," Lancet, vol. 358, no. 9283, pp. 718-723, 2001.

[115] D. Mutimer, B. H. Feraz-Neto, R. Harrison et al., "Acute liver graft failure due to emergence of lamivudine resistant hepatitis B virus: rapid resolution during treatment with adefovir," Gut, vol. 49 , no. 6 , pp. $860-863,2001$.

[116] K. M. Walsh, T. Woodall, P. Lamy, D. G. D. Wight, S. Bloor, and G. J. M. Alexander, "Successful treatment with adefovir dipivoxil in a patient with fibrosing cholestatic hepatitis and lamivudine resistant hepatitis B virus," Gut, vol. 49, no. 3, pp. 436-440, 2001.

[117] S. Mukherjee and P. Marcellin, "Adefovir dipivoxil for hepatitis B e antigen-positive chronic hepatitis B," New England Journal of Medicine, vol. 348, no. 24, p. 2468, 2003.

[118] E. R. Schiff, C. L. Lai, S. Hadziyannis et al., "Adefovir dipivoxil therapy for lamivudine-resistant hepatitis B in pre- and postliver transplantation patients," Hepatology, vol. 38, no. 6, pp. 1419-1427, 2003.

[119] S. J. Hadziyannis, N. C. Tassopoulos, E. J. Heathcote et al., "Adefovir dipivoxil for the treatment of hepatitis B e antigennegative chronic hepatitis B," New England Journal of Medicine, vol. 348, no. 9, pp. 800-807, 2003. 
[120] P. Angus, R. Vaughan, S. Xiong et al., "Resistance to adefovir dipivoxil therapy associated with the selection of a novel mutation in the HBV polymerase," Gastroenterology, vol. 125, no. 2, pp. 292-297, 2003.

[121] S. J. Hadziyannis, N. C. Tassopoulos, E. J. Heathcote et al., "Long-term therapy with adefovir dipivoxil for HBeAg-negative chronic hepatitis b for up to 5 years," Gastroenterology, vol. 131, no. 6, pp. 1743-1751, 2006.

[122] M. Seifer, R. K. Hamatake, R. J. Colonno, and D. N. Standring, "In vitro inhibition of hepadnavirus polymerases by the triphosphates of BMS-200475 and lobucavir," Antimicrobial Agents and Chemotherapy, vol. 42, no. 12, pp. 3200-3208, 1998.

[123] E. V. Genovesi, L. Lamb, I. Medina et al., "Efficacy of the carbocyclic 2 -deoxyguanosine nucleoside BMS-200475 in the woodchuck model of hepatitis B virus infection," Antimicrobial Agents and Chemotherapy, vol. 42, no. 12, pp. 3209-3217, 1998.

[124] S. F. Innaimo, M. Seifer, G. S. Bisacchi, D. N. Standring, R. Zahler, and R. J. Colonno, "Identification of BMS-200475 as a potent and selective inhibitor of hepatitis B virus," Antimicrobial Agents and Chemotherapy, vol. 41, no. 7, pp. 1444-1448, 1997.

[125] C. L. Lai, M. Rosmawati, J. Lao et al., "Entecavir is superior to lamivudine in reducing hepatitis B virus DNA in patients with chronic hepatitis B infection," Gastroenterology, vol. 123, no. 6, pp. 1831-1838, 2002.

[126] T. T. Chang, R. G. Gish, R. De Man et al., "A comparison of entecavir and lamivudine for $\mathrm{HBeAg}$-positive chronic hepatitis B," New England Journal of Medicine, vol. 354, no. 10, pp. 1001-1010, 2006.

[127] N. Leung, C. Y. Peng, H. W. Hann et al., "Early hepatitis B virus DNA reduction in hepatitis $\mathrm{B}$ e antigen-positive patients with chronic hepatitis B: a randomized international study of entecavir versus adefovir," Hepatology, vol. 49, no. 1, pp. 72-79, 2009.

[128] D. Shouval, C. L. Lai, T. T. Chang et al., "Relapse of hepatitis B in HBeAg-negative chronic hepatitis B patients who discontinued successful entecavir treatment: the case for continuous antiviral therapy," Journal of Hepatology, vol. 50, no. 2, pp. 289-295, 2009.

[129] C. L. Lai, D. Shouval, A. S. Lok et al., "Entecavir versus lamivudine for patients with $\mathrm{HBeAg}$-negative chronic hepatitis B," New England Journal of Medicine, vol. 354, no. 10, pp. 1011-1020, 2006.

[130] T. T. Chang, C. L. Lai, S. K. Yoon et al., "Entecavir treatment for up to 5 years in patients with hepatitis b e antigen-positive chronic hepatitis B," Hepatology, vol. 51, no. 2, pp. 422-430, 2010.

[131] T. T. Chang, Y. F. Liaw, S. S. Wu et al., "Long-term entecavir therapy results in the reversal of fibrosis/cirrhosis and continued histological improvement in patients with chronic hepatitis B," Hepatology, vol. 52, no. 3, pp. 886-893, 2010.

[132] R. G. Gish, T. T. Chang, C. L. Lai et al., "Hepatitis B surface antigen loss in antiviral treated patients with $\mathrm{HBeAg}(+)$ chronic hepatitis B infection: observation from antiviral-naive patients treated with entecavir and lamivudine," Hepatology, vol. 44, supplement 1, p. 558A, 2006.

[133] J. G. P. Reijnders, K. Deterding, J. Petersen et al., "Antiviral effect of entecavir in chronic hepatitis B: influence of prior exposure to nucleos(t)ide analogues," Journal of Hepatology, vol. 52, no. 4, pp. 493-500, 2010.

[134] T. T. Chang, Y. C. Chao, V. V. Gorbakov et al., "Results of up to 2 years of entecavir vs lamivudine therapy in nucleoside-naive HBeAg-positive patients with chronic hepatitis B," Journal of Viral Hepatitis, vol. 16, no. 11, pp. 784-789, 2009.
[135] D. J. Tenney, R. E. Rose, C. J. Baldick et al., "Long-term monitoring shows hepatitis $\mathrm{B}$ virus resistance to entecavir in nucleoside-naive patients is rare through 5 years-of therapy," Hepatology, vol. 49, no. 5, pp. 1503-1514, 2009.

[136] T. T. Chang, R. G. Gish, S. J. Hadziyannis et al., "A dose-ranging study of the efficacy and tolerability of entecavir in lamivudinerefractory chronic hepatitis B patients," Gastroenterology, vol. 129, no. 4, pp. 1198-1209, 2005.

[137] C. J. Baidick, D. J. Tenney, C. E. Mazzucco et al., "Comprehensive evaluation of hepatitis $\mathrm{B}$ virus reverse transcriptase substitutions associated with entecavir resistance," Hepatology, vol. 47, no. 5, pp. 1473-1482, 2008.

[138] D. J. Tenney, S. M. Levine, R. E. Rose et al., "Clinical emergence of entecavir-resistant hepatitis B virus requires additional substitutions in virus already resistant to lamivudine," Antimicrobial Agents and Chemotherapy, vol. 48, no. 9, pp. 3498-3507, 2004.

[139] C. L. Lai, N. Leung, E. K. Teo et al., "A 1-year trial of telbivudine, lamivudine, and the combination in patients with hepatitis B e antigen-positive chronic hepatitis B," Gastroenterology, vol. 129, no. 2, pp. 528-536, 2005.

[140] C. L. Lai, E. Gane, Y. F. Liaw et al., "Telbivudine versus lamivudine in patients with chronic hepatitis B," New England Journal of Medicine, vol. 357, no. 25, pp. 2576-2588, 2007.

[141] Y. F. Liaw, E. Gane, N. Leung et al., "2-Year GLOBE trial results: telbivudine is superior to lamivudine in patients with chronic hepatitis B," Gastroenterology, vol. 136, no. 2, pp. 486-495, 2009.

[142] H. L. Y. Chan, E. J. Heathcote, P. Marcellin et al., “Treatment of hepatitis B e antigen-positive chronic hepatitis with telbivudine or adefovir: a randomized trial," Annals of Internal Medicine, vol. 147, no. 11, pp. 745-754, 2007.

[143] E. J. Gane, Y. Wang, Y. F. Liaw et al., "Efficacy and safety of prolonged 3-year telbivudine treatment in patients with chronic hepatitis B," Liver International, vol. 31, no. 5, pp. 676-684, 2011.

[144] W. K. Seto, C. L. Lai, J. Fung et al., "Significance of HBV DNA levels at 12 weeks of telbivudine treatment and the 3 years treatment outcome," Journal of Hepatology, vol. 55, pp. 522-528, 2011.

[145] S. Zeuzem, E. Gane, Y. F. Liaw et al., "Baseline characteristics and early on-treatment response predict the outcomes of 2 years of telbivudine treatment of chronic hepatitis B," Journal of Hepatology, vol. 51, no. 1, pp. 11-20, 2009.

[146] X. S. Zhang, R. Jin, S. B. Zhang, and M. L. Tao, "Clinical features of adverse reactions associated with telbivudine," World Journal of Gastroenterology, vol. 14, no. 22, pp. 3549-3553, 2008.

[147] J. Goncalves, R. Laeufle, and C. Avila, "Increased risk with combination of telbivudine and pegylated-interferon alfa-2a in study CLDT600A2406, compared to uncommon rate with telbivudine monotherapy from the Novartis global database," Journal of Hepatology, vol. 50, pp. S329-S330, 2009.

[148] P. Marcellin, E. J. Heathcote, M. Buti et al., "Tenofovir disoproxil fumarate versus adefovir dipivoxil for chronic hepatitis B," New England Journal of Medicine, vol. 359, no. 23, pp. 2442-2455, 2008.

[149] E. J. Heathcote, P. Marcellin, M. Buti et al., "Three-year efficacy and safety of tenofovir disoproxil fumarate treatment for chronic hepatitis B," Gastroenterology, vol. 140, no. 1, pp. 132-143, 2011.

[150] P. Marcellin, M. Buti, Z. Krastev et al., "Continued efficacy and safety through 4 years of tenofovir disoproxil fumarate (TDF) 
treatment in $\mathrm{HBeAg}$ negative patients with chronic hepatitis B, (study 102): preliminary analysis," Hepatology, vol. 52, no. 4, supplement, p. 555A, 2010.

[151] E. J. Heathcote, E. J. Gane, R. De Man et al., "Long term (4 years) efficacy and safety of tenofovir disoproxil fumarate (TDF) treatment in HBeAG-positive patients ( $\mathrm{HBeAg}+$ ) with chronic hepatitis B, (Study 103): preliminary analysis," Hepatology, vol. 52, no. 4, supplement, p. 556A, 2010.

[152] E. Gane, S. L. Lee, E. J. Heathcote et al., "Four years efficacy and safety of tenofovir didoproxil fumarate (TDF) in Asians with $\mathrm{HBeAg}$-positive and HBeAg-negative chronic hepatitis B, (CHB), preliminary analysis," Hepatology, vol. 52, no. 4 Supplement, p. 559A, 2010.

[153] P. Marcellin, M. Buti, E. J. Gane et al., "Five years of treatment with Tenofovir DF, (TDF) for Chronic Hepatitis B, (CHB) infection is associated with sustained viral suppression and significant regression of histological fibrosis and cirrhosis," Hepatology, vol. 54, p. 1011A, 2011.

[154] D. Verhelst, M. Monge, J. L. Meynard et al., "Fanconi syndrome and renal failure induced by tenofovir: a first case report," American Journal of Kidney Diseases, vol. 40, no. 6, pp. 1331-1333, 2002.

[155] N. Leung, R. G. Gish, C. Wang et al., "A randomized, doubleblind comparison of 3 doses of emtricitabine in patients with chronic hepatitis B given 48 weeks of treatment," Hepatology, vol. 34, p. 349A, 2001.

[156] G. K. Lau and N. Leung, "Forty-eight weeks treatment with clevudine $30 \mathrm{mg}$ qd versus lamivudine $100 \mathrm{mg}$ qd for chronic hepatitis B infection: a double-blind randomized study," The Korean Journal of Hepatology, vol. 16, no. 3, pp. 315-320, 2010.

[157] B. Seigneres, C. Pichoud, P. Martin, P. Furman, C. Trepo, and F. Zoulim, "Inhibitory activity of dioxolane purine analogs on wild-type and lamivudine-resistant mutants of hepadnaviruses," Hepatology, vol. 36, no. 3, pp. 710-722, 2002.

[158] M. F. Yuen, J. Kim, C. R. Kim et al., "A randomized placebocontrolled, dose-finding study of oral LB80380 in HBeAgpositive patients with chronic hepatitis B," Antiviral Therapy, vol. 11, no. 8, pp. 977-983, 2006.

[159] M. F. Yuen, K. H. Han, S. H. Um et al., "Antiviral activity and safety of LB80380 in hepatitis B e antigen-positive chronic hepatitis B patients with lamivudine-resistant disease," Hepatology, vol. 51, no. 3, pp. 767-776, 2010.

[160] G. Y. Wu, X. J. Zheng, C. C. Yin et al., "Inhibition of hepatitis $B$ virus replication by Bay 41-4109 and its association with nucleocapsid disassembly," Journal of Chemotherapy, vol. 20, no. 4, pp. 458-467, 2008.

[161] S. J. Stray and A. Zlotnick, "BAY 41-4109 has multiple effects on hepatitis B virus capsid assembly," Journal of Molecular Recognition, vol. 19, no. 6, pp. 542-548, 2006.

[162] R. Bartenschlager, F. L. Cosset, and V. Lohmann, "Hepatitis C virus replication cycle," Journal of Hepatology, vol. 53, no. 3, pp. 583-585, 2010.

[163] E. Santolini, G. Migliaccio, and N. La Monica, "Biosynthesis and biochemical properties of the hepatitis $\mathrm{C}$ virus core protein," Journal of Virology, vol. 68, no. 6, pp. 3631-3641, 1994.

[164] J. McLauchlan, M. K. Lemberg, G. Hope, and B. Martoglio, "Intramembrane proteolysis promotes trafficking of hepatitis C virus core protein to lipid droplets," EMBO Journal, vol. 21, no. 15, pp. 3980-3988, 2002.

[165] V. Pène, C. Hernandez, C. Vauloup-Fellous, J. Garaud-Aunis, and A. R. Rosenberg, "Sequential processing of hepatitis $C$ virus core protein by host cell signal peptidase and signal peptide peptidase: a reassessment," Journal of Viral Hepatitis, vol. 16, no. 10, pp. 705-715, 2009.

[166] J. L. Kim, K. A. Morgenstern, J. P. Griffith et al., "Hepatitis C virus NS3 RNA helicase domain with a bound oligonucleotide: the crystal structure provides insights into the mode of unwinding," Structure, vol. 6, no. 1, pp. 89-100, 1998.

[167] V. Lohmann, F. Körner, J. O. Koch, U. Herian, L. Theilmann, and R. Bartenschlager, "Replication of subgenomic hepatitis $C$ virus RNAs in a hepatoma cell line," Science, vol. 285, no. 5424, pp. 110-113, 1999.

[168] T. Wakita, T. Pietschmann, T. Kato et al., "Production of infectious hepatitis $\mathrm{C}$ virus in tissue culture from a cloned viral genome," Nature Medicine, vol. 11, no. 7, pp. 791-796, 2005, Erratum: Nature Medicine, vol. 11, no. 8, pp. 905, 2005.

[169] A. Merz, G. Long, M. S. Hiet et al., "Biochemical and morphological properties of hepatitis $C$ virus particles and determination of their lipidome," Journal of Biological Chemistry, vol. 286, no. 4, pp. 3018-3032, 2011.

[170] E. Scarselli, H. Ansuini, R. Cerino et al., "The human scavenger receptor class $\mathrm{B}$ type $\mathrm{I}$ is a novel candidate receptor for the hepatitis C virus," EMBO Journal, vol. 21, no. 19, pp. 5017-5025, 2002.

[171] P. Pileri, Y. Uematsu, S. Campagnoli et al., "Binding of hepatitis C virus to CD81," Science, vol. 282, no. 5390, pp. 938-941, 1998.

[172] M. J. Evans, T. Von Hahn, D. M. Tscherne et al., "Claudin-1 is a hepatitis $\mathrm{C}$ virus co-receptor required for a late step in entry," Nature, vol. 446, no. 7137, pp. 801-805, 2007.

[173] A. Ploss, M. J. Evans, V. A. Gaysinskaya et al., "Human occludin is a hepatitis $\mathrm{C}$ virus entry factor required for infection of mouse cells," Nature, vol. 457, no. 7231, pp. 882-886, 2009.

[174] J. Lupberger, M. B. Zeisel, F. Xiao et al., "EGFR and EphA2 are host factors for hepatitis $\mathrm{C}$ virus entry and possible targets for antiviral therapy," Nature Medicine, vol. 17, no. 5, pp. 589-595, 2011.

[175] B. Sainz Jr., N. Barretto, D. N. Martin et al., "Identification of the Niemann-Pick C1-like 1 cholesterol absorption receptor as a new hepatitis C virus entry factor," Nature Medicine, vol. 18, pp. 281-285, 2012.

[176] L. Meertens, C. Bertaux, L. Cukierman et al., “The tight junction proteins claudin-1, -6 , and -9 are entry cofactors for hepatitis $C$ virus," Journal of Virology, vol. 82, no. 7, pp. 3555-3560, 2008.

[177] K. E. Coller, K. L. Berger, N. S. Heaton, J. D. Cooper, R. Yoon, and G. Randall, "RNA interference and single particle tracking analysis of hepatitis C virus endocytosis," PLoS Pathogens, vol. 5, no. 12, Article ID e1000702, 2009.

[178] E. Blanchard, S. Belouzard, L. Goueslain et al., "Hepatitis C virus entry depends on clathrin-mediated endocytosis," Journal of Virology, vol. 80, no. 14, pp. 6964-6972, 2006.

[179] J. McLauchlan, "Lipid droplets and hepatitis C virus infection," Biochimica et Biophysica Acta, vol. 1791, no. 6, pp. 552-559, 2009.

[180] C. I. Popescu, Y. Rouille, and J. Dubuisson, "Hepatitis C virus assembly imaging," Viruses, vol. 3, pp. 2238-2254, 2011.

[181] P. Gastaminza, G. Cheng, S. Wieland, J. Zhong, W. Liao, and F. V. Chisari, "Cellular determinants of hepatitis c virus assembly, maturation, degradation, and secretion," Journal of Virology, vol. 82, no. 5, pp. 2120-2129, 2008.

[182] C. T. Jones, C. L. Murray, D. K. Eastman, J. Tassello, and C. M. Rice, "Hepatitis C virus $\mathrm{p} 7$ and NS2 proteins are essential for production of infectious virus," Journal of Virology, vol. 81, no. 16, pp. 8374-8383, 2007. 
[183] E. Steinmann, F. Penin, S. Kallis, A. H. Patel, R. Bartenschlager, and T. Pietschmann, "Hepatitis $\mathrm{C}$ virus $\mathrm{p} 7$ protein is crucial for assembly and release of infectious virions," PLoS pathogens, vol. 3, no. 7, article e103, 2007.

[184] M. Yi, Y. Ma, J. Yates, and S. M. Lemon, "trans-complementation of an NS2 defect in a late step in hepatitis C virus (HCV) particle assembly and maturation," PLoS Pathogens, vol. 5, no. 5, Article ID e1000403, 2009.

[185] H. Huang, F. Sun, D. M. Owen et al., "Hepatitis C virus production by human hepatocytes dependent on assembly and secretion of very low-density lipoproteins," Proceedings of the National Academy of Sciences of the United States of America, vol. 104, no. 14, pp. 5848-5853, 2007.

[186] K. S. Chang, J. Jiang, Z. Cai, and G. Luo, "Human apolipoprotein $\mathrm{E}$ is required for infectivity and production of hepatitis $\mathrm{C}$ virus in cell culture," Journal of Virology, vol. 81, no. 24, pp. 13783-13793, 2007.

[187] A. Kaul, S. Stauffer, C. Berger et al., "Essential role of cyclophilin A for hepatitis $\mathrm{C}$ virus replication and virus production and possible link to polyprotein cleavage kinetics," PLoS Pathogens, vol. 5, no. 8, Article ID e1000546, 2009.

[188] F. Yang, J. M. Robotham, H. B. Nelson, A. Irsigler, R. Kenworthy, and H. Tang, "Cyclophilin A is an essential cofactor for hepatitis $\mathrm{C}$ virus infection and the principal mediator of cyclosporine resistance in vitro," Journal of Virology, vol. 82, no. 11, pp. 5269-5278, 2008.

[189] S. Reiss, I. Rebhan, P. Backes et al., "Recruitment and activation of a lipid kinase by hepatitis C virus NS5A is essential for integrity of the membranous replication compartment," Cell Host and Microbe, vol. 9, no. 1, pp. 32-45, 2011.

[190] T. Kuntzen, J. Timm, A. Berical et al., "Naturally occurring dominant resistance mutations to hepatitis $\mathrm{C}$ virus protease and polymerase inhibitors in treatment-naïve patients," Hepatology, vol. 48, no. 6, pp. 1769-1778, 2008.

[191] M. P. Manns, J. G. McHutchison, S. C. Gordon et al., "Peginterferon alfa- $2 \mathrm{~b}$ plus ribavirin compared with interferonalfa$2 \mathrm{~b}$ plus ribavirin for initial treatment of chronic hepatitis C: a randomised trial," Lancet, vol. 358, no. 9286, pp. 958-965, 2001.

[192] M. W. Fried, ShiffmanML, K. R. Reddy et al., "Peginterferon alfa-2a plus ribavirin for chronic hepatitis C virus infection," The New England Journal of Medicine, vol. 347, pp. 975-982, 2002.

[193] E. Thomas, J. J. Feld, Q. Li, Z. Hu, M. W. Fried, and T. J. Liang, "Ribavirin potentiates interferon action by augmenting interferon-stimulated gene induction in hepatitis $\mathrm{C}$ virus cell culture models," Hepatology, vol. 53, no. 1, pp. 32-41, 2011.

[194] I. M. Jacobson, R. S. Brown, and B. Freilich, "Peginterferon a2b and weight-based or flat-dose ribavirin in chronic hepatitis $\mathrm{C}$ patients: a randomized trial," Hepatology, vol. 46, pp. 971-981, 2007.

[195] P. Glue, R. Rouzier-Panis, C. Raffanel et al., "A dose-ranging study of pegylated interferon alfa- $2 \mathrm{~b}$ and ribavirin in chronic hepatitis C," Hepatology, vol. 32, no. 3, pp. 647-653, 2000.

[196] M. G. Swain, M. Lai, M. L. Shiffman et al., "A sustained virologic response is durable in patients with chronic hepatitis $\mathrm{C}$ treated with peginterferon Alfa-2a and ribavirin," Gastroenterology, vol. 139, no. 5, pp. 1593-1601, 2010.

[197] M. G. Ghany, D. B. Strader, D. L. Thomas, and L. B. Seeff, "Diagnosis, management, and treatment of hepatitis C: an update," Hepatology, vol. 49, no. 4, pp. 1335-1374, 2009.

[198] C. F. Huang, J. F. Yang, C. Y. Dai et al., "Efficacy and safety of pegylated interferon combined with ribavirin for the treatment of older patients with chronic hepatitis C," Journal of Infectious Diseases, vol. 201, no. 5, pp. 751-759, 2010.

[199] I. M. Jacobson, R. S. Brown, J. McCone et al., "Impact of weight-based ribavirin with peginterferon alfa-2b in African Americans with hepatitis C virus genotype 1," Hepatology, vol. 46, no. 4, pp. 982-990, 2007.

[200] J. G. Mchutchison, S. C. Gordon, E. R. Schiff et al., "Interferon alfa- $2 \mathrm{~b}$ alone or in combination with ribavirin as initial treatment for chronic hepatitis C," New England Journal of Medicine, vol. 339, no. 21, pp. 1485-1492, 1998.

[201] J. G. McHutchison, E. J. Lawitz, M. L. Shiffman et al., "Peginterferon alfa-2b or alfa-2a with ribavirin for treatment of hepatitis C infection," New England Journal of Medicine, vol. 361, no. 6, pp. 580-593, 2009.

[202] D. Ge, J. Fellay, A. J. Thompson et al., "Genetic variation in IL28B predicts hepatitis C treatment-induced viral clearance," Nature, vol. 461, no. 7262, pp. 399-401, 2009.

[203] C. Hézode, N. Forestier, G. Dusheiko et al., "Telaprevir and peginterferon with or without ribavirin for chronic $\mathrm{HCV}$ infection," New England Journal of Medicine, vol. 360, no. 18, pp. 1839-1850, 2009.

[204] J. G. McHutchison, G. T. Everson, S. C. Gordon et al., "Telaprevir with peginterferon and ribavirin for chronic HCV genotype 1 infection," New England Journal of Medicine, vol. 360, no. 18, pp. 1827-1838, 2009.

[205] J. G. McHutchison, M. P. Manns, A. J. Muir et al., "Telaprevir for previously treated chronic HCV infection," New England Journal of Medicine, vol. 362, no. 14, pp. 1292-1303, 2010.

[206] S. Zeuzem, C. Hezode, P. Ferenci et al., "Telaprevir in combination with peginterferon alfa- 2 a with or without ribavirin in the treatment of chronic hepatitis C. Final results of the PROVE 2 study," Hepatology, vol. 48, supplement 1, pp. 418-419, 2008.

[207] M. S. Sulkowski, S. Roberts, N. Afdhal et al., “. Ribavirin dose modification in treatment-naive and previously treated patients who received telaprevir combination treatment: no impact on sustained virologic response in phase 3 studies," Journal of Hepatology, vol. 56, supplement 2, p. A1162, 2012.

[208] K. E. Sherman, S. Flamm, N. H. Afdhal et al., "Telaprevir in combination with peginterferon alfa2a and ribavirin for 24 or 48 weeks in treatment-naive genotype $1 \mathrm{HCV}$ patients who achieved an extended rapid viral response: final results of phase 3 ILLUMINATE," Study. Hepatology, vol. 52, supplement 4, article LB-2, 2010.

[209] S. Zeuzem, P. Andreone, S. Pol et al., "Telaprevir for retreatment of HCV infection," New England Journal of Medicine, vol. 364, no. 25, pp. 2417-2428, 2011.

[210] P. Y. Kwo, E. J. Lawitz, J. McCone et al., "SPRINT-1 investigators. Efficacy of boceprevir, an NS3 protease inhibitor, in combination with peginterferon alfa- $2 \mathrm{~b}$ and ribavirin in treatment-naïve patients with genotype 1 hepatitis $\mathrm{C}$ infection (SPRINT-1): an open-label, randomised, multicentre phase 2 trial," Lancet, vol. 376, pp. 705-716, 2010.

[211] F. Poordad, J. McCone, B. R. Bacon et al., "Boceprevir for untreated chronic HCV genotype 1 infection," New England Journal of Medicine, vol. 364, no. 13, pp. 1195-1206, 2011.

[212] B. R. Bacon, S. C. Gordon, E. Lawitz et al., "Boceprevir for previously treated chronic HCV genotype 1 infection," New England Journal of Medicine, vol. 364, no. 13, pp. 1207-1217, 2011.

[213] T. L. Kieffer, C. Sarrazin, J. S. Miller et al., "Telaprevir and pegylated interferon-alpha-2a inhibit wild-type and resistant 
genotype 1 hepatitis C virus replication in patients," Hepatology, vol. 46, no. 3, pp. 631-639, 2007.

[214] S. Susser, C. Welsch, Y. Wang et al., "Characterization of resistance to the protease inhibitor boceprevir in hepatitis $\mathrm{C}$ virusinfected patients," Hepatology, vol. 50, no. 6, pp. 1709-1718, 2009.

[215] J. A. Howe, P. Qiu, R. A. Ogert et al., "Frequencies of resistance associated amino acid variants detected by 454-sequencing during combination treatment with boceprevir plus PegIntron (peginterferon alfa-2b)/ribavirin in HCV, (GT1)-infected patients," Journal of Hepatology, vol. 54, supplemen 1, p. 176, 2011.

[216] S. Zeuzem, M. Sulkowski, F. Zoulim et al., "Long-term follow up of patients with chronic hepatitis $\mathrm{C}$ treated with telaprevir in combination with peginterferon alfa- $2 \mathrm{~A}$ and ribavirin: interim analysis of the EXTEND study," Hepatology, vol. 52, supplement 1, p. 436A, 2010.

[217] H. W. Reesink, G. C. Fanning, K. A. Farha et al., "Rapid HCVRNA decline with once daily TMC435: a phase I study in healthy volunteers and hepatitis C patients," Gastroenterology, vol. 138, no. 3, pp. 913-921, 2010.

[218] J. M. Gottwein, T. K. Scheel, T. B. Jensen et al., “. Differential efficacy of protease inhibitors against HCV genotypes 2a, 3a, 5a, and 6a NS3/4A protease recombinant viruses," Gastroenterology, vol. 141, pp. 1067-1079, 2011.

[219] Y. S. Tsantrizos, "TMC-435, an NS3/4A protease inhibitor for the treatment of HCV infection," Current Opinion in Investigational Drugs, vol. 10, no. 8, pp. 871-881, 2009.

[220] S. Zeuzem, T. Berg, E. Gane P et al., "TMC435 in HCV genotype 1 patients who have failed previous pegylated interferon/ribavirin treatment: final SVR24 results of the aspire trial," Journal of Hepatology, vol. 56, supplement 2, p. A2, 2012.

[221] N. Forestier, D. Larrey, P. Marcellin et al., "Antiviral activity of danoprevir (ITMN-191/RG7227) in combination with pegylated interferon $\alpha$-2a and ribavirin in patients with hepatitis C," Journal of Infectious Diseases, vol. 204, no. 14, pp. 601-608, 2011.

[222] E. J. Gane, R. Rouzier, C. Stedman et al., "Antiviral activity, safety, and pharmacokinetics of danoprevir/ritonavir plus PEGIFN alpha-2a/RBV in hepatitis C patients," Journal of Hepatology, vol. 55, pp. 972-979, 2011.

[223] S. Zeuzem, T. Asselah, P. Angus et al., "Efficacy of the protease inhibitor BI, 201335, polymerase inhibitor BI, 207127, and ribavirin in patients with chronic HCV infection," Gastroenterology, vol. 141, pp. 2047-2055, 2011.

[224] F. E. Membreno and E. J. Lawitz, "The HCV NS5B nucleoside and nonnucleoside inhibitors," Clinics in Liver Disease, vol. 15, pp. 611-626, 2011.

[225] A. M. Lam, C. Espiritu, S. Bansal et al., "HCV nucleotide inhibitors PSI-352938 and PSI-353661 exhibit a novel mechanism of resistance requiring multiple mutations within replicon RNA," Journal of Virology, vol. 85, pp. 12334-12342, 2011.

[226] J. Lalezari, E. Lawitz, M. Rodriguez-Torres et al., "Once daily PSI-7977 plus PegIFN/RBV in a phase 2B trial: rapid virologic suppression in treatment-naïve patients with HCV GT2/GT3," Journal of Hepatology, vol. 54, supplement 1, p. A61, 2011.

[227] K. V. Kowdlev, E. Läwitz, I. Crespo et al., "Atomic: 97\% RVR for PSI-7977 + PEG/RBV $\times 12$ week regimen in HCV gt1: an end to response-guided therapy?" Journal of Hepatology, vol. 56, supplement 2, p. A1, 2012.

[228] H. Wedemeyer, D. Jensen, R. Herring et al., "Efficacy and safety of mericitabine (MCB) in combination with Peg-IFNa-2a/RBV in g1/4 treatment naive HCV patients: final analysis from the propel study," Journal of Hepatology, vol. 56, supplement 2, p. A1213, 2012.

[229] P. Pockros, D. Jensen, N. Tsai R et al., “. SVR-12 among G1/4 treatment-naive patients receiving mericitabine in combination with Peg-IFNa-2a/RBV: interim analysis from the JUMP-C study," Journal of Hepatology, vol. 56, supplement 2, p. A1205, 2012.

[230] E. Lawitz, I. Jacobson, E. Godofsky et al., “. A Phase 2b trial comparing 24 to 48 weeks of treatment with tegobuvir (GS-9190)/PEG/RV to 48 weeks treatment with PEG/RBV for chronic genotype $1 \mathrm{HCV}$ infection," Journal of Hepatology, vol. 54, supplemen 1, p. A445, 2011.

[231] S. Einav, D. Gerber, P. D. Bryson et al., "Discovery of a hepatitis $\mathrm{C}$ target and its pharmacological inhibitors by microfluidic affinity analysis," Nature Biotechnology, vol. 26, no. 9, pp. 1019-1027, 2008.

[232] R. A. Fridell, D. Qiu, L. Valera, C. Wang, R. E. Rose, and M. Gao, "Distinct functions of NS5A in hepatitis C virus RNA replication uncovered by studies with the NS5A Inhibitor BMS790052," Journal of Virology, vol. 85, no. 14, pp. 7312-7320, 2011.

[233] P. Ferraris, E. Blanchard, and P. Roingeard, "Ultrastructural and biochemical analyses of hepatitis C virus-associated host cell membranes," Journal of General Virology, vol. 91, no. 9, pp. 2230-2237, 2010.

[234] A. Macdonald and M. Harris, "Hepatitis C virus NS5A: tales of a promiscuous protein," Journal of General Virology, vol. 85, no. 9, pp. 2485-2502, 2004.

[235] K. H. Lan, K. L. Lan, W. P. Lee et al., "HCV NS5A inhibits interferon- $\alpha$ signaling through suppression of STAT1 phosphorylation in hepatocyte-derived cell lines," Journal of Hepatology, vol. 46, no. 5, pp. 759-767, 2007.

[236] R. G. Gish and N. A. Meanwell, "The NS5A replication complex inhibitors: difference makers?” Clinics in Liver Disease, vol. 15, pp. 627-639, 2011.

[237] S. Pol, R. H. Ghalib, V. K. Rustgi et al., "First report of SVR12 for a NS5A replication complex inhibitor, BMS-790052 in combination with peg-IFN-alfa-2a and RBV: phase $2 \mathrm{a}$ trial in treatment-naive HCV-genotype 1 subjects," Journal of Hepatology, vol. 54, supplement 1, p. A2, 2011.

[238] G. J. Sullivan, M. Rodriques-Torres, E. Lawitz F et al., "ABT267 combined with pegylated interferon alpha-2a/ribavirin in genotype 1 (gt1) HCV-infected treatment-naive subjects: 12 week antiviral and safety analysis," Journal of Hepatology, vol. 56, supplement 2, p. A1210, 2012.

[239] S. Zeuzem, P. Buggisch, K. Agarwal et al., "Dual, triple, and quadruple combination treatment with a protease inhibitor (GS-9256) and a polymerase inhibitor (GS-9190) alone and in combination with ribavirin (RBV) or PegIFN/RBV for up to 28 days in treatment naive, genotype $1 \mathrm{HCV}$ subjects," in Proceedings of the 61th Annual Meeting of the American Association for the Study of Liver Diseases (AASLD '10), LB-1, Boston, Mass, USA, 2010.

[240] G. R. Foster, P. Buggisch, P. Marcellin et al., "Four-week treatment with GS-9256 and tegobuvir (GS-9190), \pm RBV \pm PEG, results in enhanced viral suppression on follow-up PEG/RBV therapy, in genotype $1 \mathrm{a} / \mathrm{lb}$ HCV patients," Journal of Hepatology, vol. 54, supplement 1, p. A232, 2011.

[241] D. R. Nelson, E. J. Gane, I. M. Jacobson et al., "VX$222 /$ telaprevir in combination with peginterferon-alfa-2a and ribavirin in treatment naïve genotype $1 \mathrm{HCV}$ patients treated 
for 12 weeks: ZENITH study, SVR12 interim analysis," in Proceedings of the 61th Annual Meeting of the American Association for the Study of Liver Diseases (AASLD '11), LB-14, San Francisco, Calif, USA, 2011.

[242] E. Z. Zhang, A. Tigges, M. Jiang et al., "Characterization of HCV variants in genotype 1 treatment-naive patients administered the combination of TVR and VX-222 in dual arms of zenith study," Journal of Hepatology, vol. 56, supplement 2, p. A1184, 2012.

[243] A. Lok, D. Gardiner, E. Lawitz et al., "Preliminary study of two antiviral agents for hepatitis C genotype 1," The New England Journal of Medicine, vol. 366, pp. 216-224, 2012.

[244] A. Lok, D. Gardiner, E. Lawitz et al., "Quadruple therapy with BMS-790052, BMS-650032 and PEG-IFN/RBV for 24 weeks results in $100 \%$ SVR12 in HCV genotype 1 null responders," Journal of Hepatology, vol. 54, supplement 1, p. S536, 2011.

[245] E. Lawitz, F. Poordad, E. DeJesus et al., "ABT-450/Ritonavir (ABT-450/R) combined with pegylated interferon alpha2a/ribavirin after 3-day monotherapy in genotype 1 (gt1) hcvinfected treatment-naive subjects: 12 -week sustained virologic response (SVR12) and safety results," Journal of Hepatology, vol. 56, supplement 2, p. A1187, 2012.

[246] G. Everson, C. Cooper, C. Hezode et al., "Rapid and sustained achievement of undetectable HCV RNA during treatment with Ritonavir-boosted Danoprevir/PEG-IFNa-2A/RBV in HCV genotype 1 or 4 patients: DAUPHINE week 12 interim analysis," Journal of Hepatology, vol. 56, supplement 2, p. A1177, 2012.

[247] D. R. Nelson, E. Lawitz, V. Bain et al., "High SVR12 with 16 weeks of Tegobuvir and GS-9256 with peginterferon-alfa $2 \mathrm{a}$ and ribavirin in treatment-naive genotype $1 \mathrm{HCV}$ patients," Journal of Hepatology, vol. 56, supplement 2, p. A12, 2012.

[248] E. Gane, C. A. Stedman, R. H. Hyland et al., "Once daily PSI-7977 plus RBV: pegylated interferon alfa not required for complete rapid viral response in treatment-naive patients with HCV GT2 or 3," in Proceedings of the 61th Annual Meeting of the American Association for the Study of Liver Diseases (AASLD '11), San Francisco, Calif, USA, 2011.

[249] F. Suzuki, K. Ikeda, J. Toyota et al., "Dual oral therapy with the NS5A inhibitor Daclatasvir (BMS-790052) and NS3 protease inhibitor Asunaprevir (BMS-650032) in HCV genotype 1binfected null responders or ineligible/intolerant to peginterferon/ribavirin," Journal of Hepatology, vol. 56, supplement 2, p. A14, 2012.

[250] M. Sulkowski, D. Gardiner, E. Lawitz et al., "Potent viral suppression with the all oral combination of Daclatasvir and GS-7977, +/- ribavirin, in treatment naive patients with chronic GT1, 2, or 3," in Proceedings of the 47th annual meeting of the European Association for the Study of the Liver (EASL '12), P1422, Barcelona, Spain, 2012.

[251] S. Zeuzem, V. Soriano, T. Asselah et al., "SVR4 and SVR12 with an interferon-free regimen of BI201335 and BI207127, +/ribavirin, in treatment-naive patients with chronic genotype$1 \mathrm{HCV}$ infection: interim results of SOUND-C2," Journal of Hepatology, vol. 56, supplement 2, p. A101, 2012.

[252] V. Soriano, E. Gane, P. Angus et al., "The efficacy and safety of the interferon-free combination of BI201335 AND BI207127 in genotype $1 \mathrm{HCV}$ PATIENTS with cirrhosis-interim analysis from SOUND-C2," Journal of Hepatology, vol. 56, supplement 2, p. A1420, 2012.

[253] E. Lawitz, F. Poordad, K. V. Kowdley et al., "A 12-week interferon-free regimen of ABT-450/R, ABT-072, and ribavirin was well tolerated and achieved sustained virologic response in $91 \%$ treatment-naive HCV IL28B-CC genotype-1-infected subjects," Journal of Hepatology, vol. 56, supplement 2, p. A13, 2012.

[254] M. Sulkowski, M. Rodriguez-Torres, E. Lawitz et al., "High sustained virologic response rate in treatment-naive $\mathrm{HCV}$ genotype $1 \mathrm{a}$ and $1 \mathrm{~b}$ patients treated for 12 weeks with an interferon-free all-oral quad regimen: interim results," Journal of Hepatology, vol. 56, supplement 2, p. A1421, 2012.

[255] X. Hanoulle, A. Badillo, J. M. Wieruszeski et al., "Hepatitis $\mathrm{C}$ virus NS5A protein is a substrate for the peptidyl-prolyl cis/trans isomerase activity of cyclophilins A and B," Journal of Biological Chemistry, vol. 284, no. 20, pp. 13589-13601, 2009.

[256] S. Hopkins, B. Scorneaux, Z. Huang et al., "SCY-635, a novel nonimmunosuppressive analog of cyclosporine that exhibits potent inhibition of Hepatitis C virus RNA replication in vitro," Antimicrobial Agents and Chemotherapy, vol. 54, no. 2, pp. 660-672, 2010.

[257] S. Hopkins, S. Mosier, R. Harris et al., "Resistance selection following 15 days of monotherapy with SCY-635 a nonimmunosuppressive cyclophilin inhibitor with potent antiHCV activity," Journal of Hepatology, vol. 52, supplement 1, p. A34, 2010.

[258] L. Coelmont, X. Hanoulle, U. Chatterji et al., "Deb025 (Alisporivir) inhibits hepatitis $\mathrm{c}$ virus replication by preventing a cyclophilin a induced Cis-trans isomerisation in domain ii of NS5A," PLoS One, vol. 5, no. 10, Article ID e13687, 2010.

[259] R. Flisiak, J. M. Pawlotsky, R. Crabbe et al., "Once daily alisporivir (DEB025) plus PegIFNalfa2A/ribavirin results in superior sustained virologic response (SVR24) in chronic hepatitis C genotype 1 treatment naive patients," Journal of Hepatology, vol. 54, supplement 1, p. A4, 2011.

[260] C. L. Jopling, M. Yi, A. M. Lancaster, S. M. Lemon, and P. Sarnow, "Molecular biology: modulation of hepatitis $\mathrm{C}$ virus RNA abundance by a liver-specific MicroRNA," Science, vol. 309, no. 5740, pp. 1577-1581, 2005.

[261] R. E. Lanford, E. S. Hildebrandt-Eriksen, A. Petri et al., “Therapeutic silencing of microRNA-122 in primates with chronic hepatitis C virus infection," Science, vol. 327, no. 5962, pp. 198-201, 2010.

[262] A. K. Patick, A. Chen, L. J. van Doorn et al., "Sequence analysis of hcv variants from a phase IIA trial of Miravirsen (MIR), an oligonucleotide targeting MIR-122, in treatment naive patients with chronic HCV infection," Journal of Hepatology, vol. 56, supplement 2, A1202 pages, 2012.

[263] H. Zhu, F. Wong-Staal, H. Lee et al., "Evaluation of ITX, 5061, a scavenger receptor $\mathrm{B} 1$ antagonist: resistance selection and activity in combination with other hepatitis C virus antivirals," The Journal of Infectious Diseases, vol. 205, pp. 656-662, 2012.

[264] M. Rizzetto, "Hepatitis D: thirty years after," Journal of Hepatology, vol. 50, no. 5, pp. 1043-1050, 2009.

[265] G. Saracco, F. Rosina, M. R. Brunetto et al., "Rapidly progressive HBsAg-positive hepatitis in Italy. The role of hepatitis delta virus infection," Journal of Hepatology, vol. 5, no. 3, pp. 274-281, 1987.

[266] G. Fattovich, S. Boscaro, and F. Noventa, "Influence of hepatitis delta virus infection on progression to cirrhosis in chronic hepatitis type B," Journal of Infectious Diseases, vol. 155, no. 5, pp. 931-935, 1987.

[267] R. Romeo, E. Del Ninno, M. Rumi et al., "A 28-year study of the course of hepatitis $\Delta$ infection: a risk factor for cirrhosis and 
hepatocellular carcinoma," Gastroenterology, vol. 136, no. 5, pp. 1629-1638, 2009.

[268] C. Sureau, "The role of the HBV envelope proteins in the HDV replication cycle," Current Topics in Microbiology and Immunology, vol. 307, pp. 113-131, 2006.

[269] K. S. Wang, Q. L. Choo, and A. J. Weiner, "Structure, sequence and expression of the hepatitis delta $(\delta)$ viral genome," Nature, vol. 323 , no. 6088 , pp. 508-514, 1986.

[270] H. N. Wu, Y. J. Lin, F. P. Lin, S. Makino, M. F. Chang, and M. M. C. Lai, "Human hepatitis $\delta$ virus RNA subfragments contain an autocleavage activity," Proceedings of the National Academy of Sciences of the United States of America, vol. 86, no. 6, pp. 1831-1835, 1989.

[271] Y. J. Li, T. Macnaughton, L. Gao, and M. M. C. Lai, "RNAtemplated replication of hepatitis delta virus: genomic and antigenomic RNAs associate with different nuclear bodies," Journal of Virology, vol. 80, no. 13, pp. 6478-6486, 2006.

[272] J. Taylor and M. Pelchat, "Origin of hepatitis virus," Future Microbiology, vol. 5, no. 3, pp. 393-402, 2010.

[273] A. J. Weiner, Q. L. Choo, K. S. Wang et al., "A single antigenomic open reading frame of the hepatitis delta virus encodes the epitope(s) of both hepatitis delta antigen polypeptides p24 $(\delta)$ and p27( $\delta)$," Journal of Virology, vol. 62, no. 2, pp. 594-599, 1988.

[274] M. F. Chang, C. J. Chen, and S. C. Chang, "Mutational analysis of delta antigen: effect on assembly and replication of hepatitis delta virus," Journal of Virology, vol. 68, no. 2, pp. 646-653, 1994.

[275] S. J. Hadziyannis, "Use of $\alpha$-interferon in the treatment of chronic delta hepatitis," Journal of Hepatology, vol. 13, supplement 1, pp. S21-S26, 1991.

[276] P. Farci, T. Roskams, L. Chessa et al., "Long-term benefit of interferon $\alpha$ therapy of chronic hepatitis D: regression of advanced hepatic fibrosis," Gastroenterology, vol. 126, no. 7, pp. 1740-1749, 2004.

[277] G. A. Niro, A. Ciancio, G. B. Gaeta et al., "Pegylated interferon alpha-2b as monotherapy or in combination with ribavirin in chronic hepatitis delta," Hepatology, vol. 44, no. 3, pp. 713-720, 2006.

[278] A. Erhardt, W. Gerlich, C. Starke et al., "Treatment of chronic hepatitis delta with pegylated interferon- $\alpha 2 b$," Liver International, vol. 26, no. 7, pp. 805-810, 2006.

[279] C. Castelnau, F. Le Gal, M. P. Ripault et al., "Efficacy of peginterferon alpha-2b in chronic hepatitis delta: relevance of quantitative RT-PCR for follow-up," Hepatology, vol. 44, no. 3, pp. 728-735, 2006.

[280] F. Gunsar, U. S. Akarca, G. Ersoz et al., "Two-year interferon therapy with or without ribavirin in chronic delta hepatitis," Antiviral Therapy, vol. 10, no. 6, pp. 721-726, 2005.

[281] H. Wedemeyer, C. Yurdaydìn, G. N. Dalekos et al., "Peginterferon plus adefovir versus either drug alone for hepatitis delta," New England Journal of Medicine, vol. 364, no. 4, pp. 322-331, 2011.

[282] C. Yurdaydin, H. Bozkaya, F. O. Önder et al., "Treatment of chronic delta hepatitis with lamivudine vs lamivudine + interferon vs interferon," Journal of Viral Hepatitis, vol. 15, no. 4, pp. 314-321, 2008.

[283] J. S. Glenn, J. A. Watson, C. M. Havel, and J. M. White, "Identification of a prenylation site in delta virus large antigen," Science, vol. 256, no. 5061, pp. 1331-1333, 1992.

[284] B. B. Bordier, J. Ohkanda, P. Liu et al., "In vivo antiviral efficacy of prenylation inhibitors against hepatitis delta virus," Journal of Clinical Investigation, vol. 112, no. 3, pp. 407-414, 2003. 

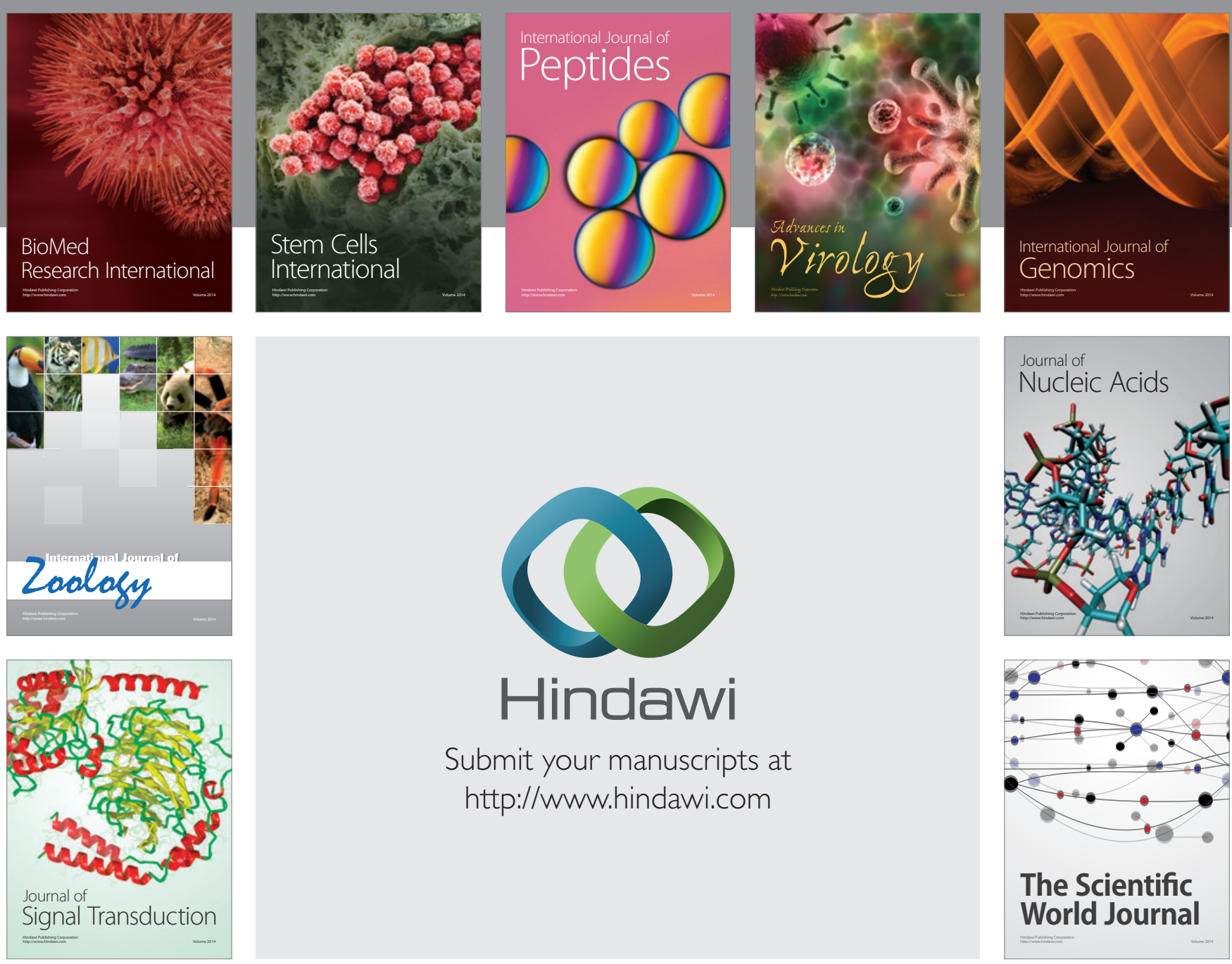

Submit your manuscripts at

http://www.hindawi.com
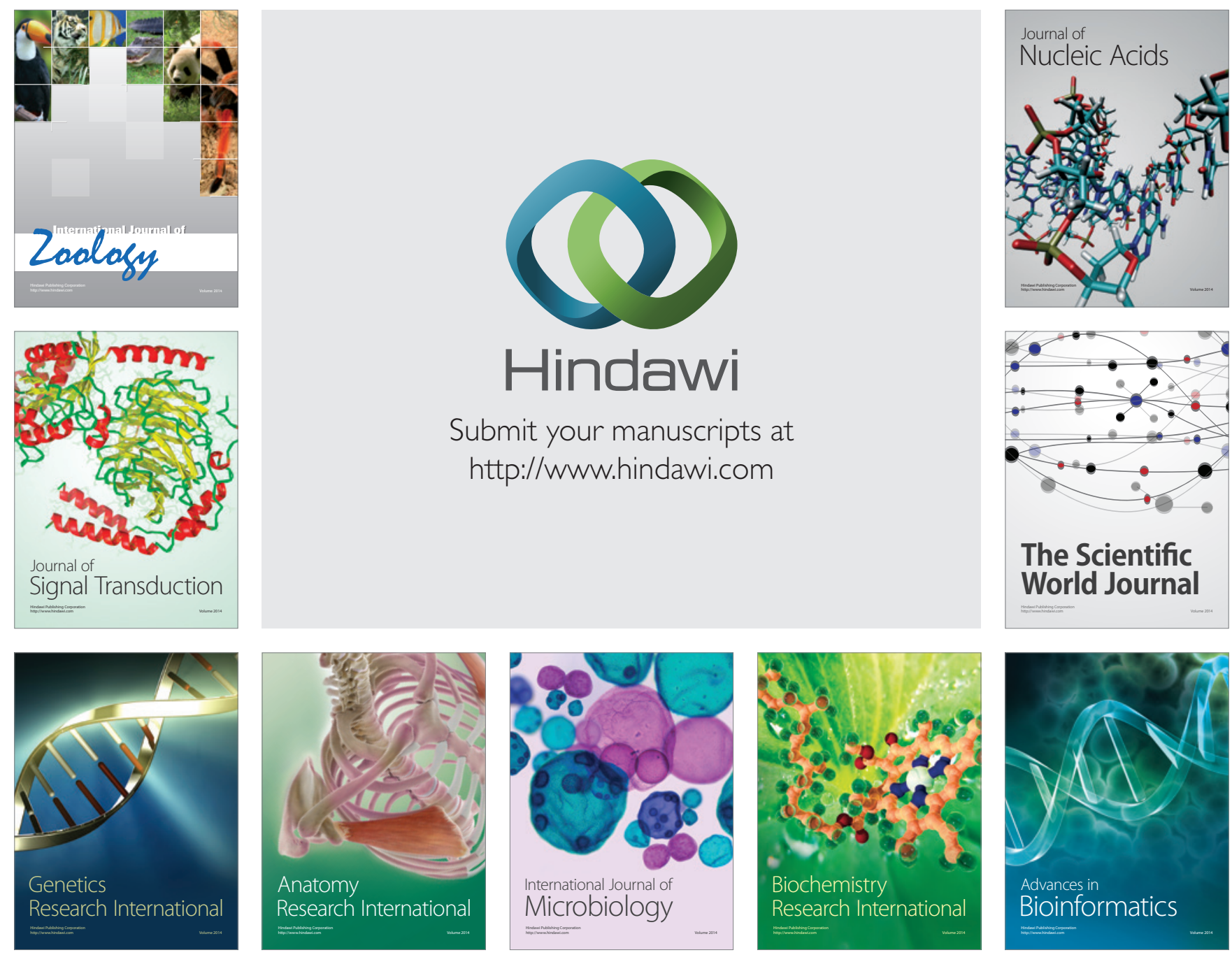

The Scientific World Journal
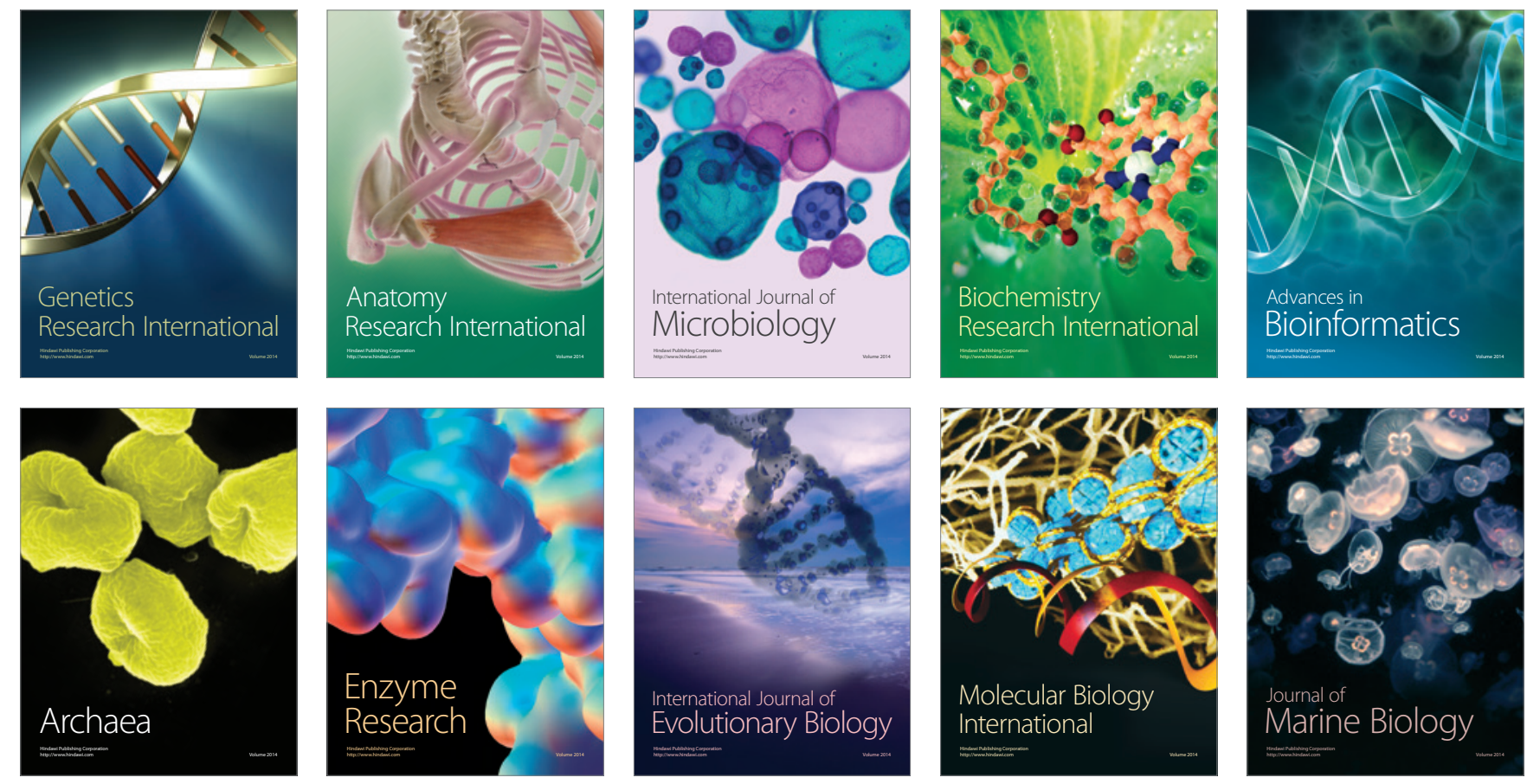